\title{
EFFECT OF SULPHUR POISONING ON PEROVSKITE CATALYSTS PREPARED BY FLAME-PYROLYSIS
}

Ilenia Rossetti”, Olga Buchneva, Cesare Biffi, Riccardo Rizza

Dip. Chimica Fisica ed Elettrochimica, Università degli Studi di Milano

v. C. Golgi, 19, I-20133 Milano, Italy

\section{ABSTRACT}

$\mathrm{ABO}_{3}$ perovskite-like catalysts are known to be sensitive to sulphur-containing compounds. Possible solutions to increase resistance to sulphur are represented by either catalyst bed protection with basic guards or catalyst doping with different transition or noble metals. In the present work $\mathrm{La}_{(1-x)} \mathrm{A}^{\prime} \times \mathrm{CoO}_{3}, \mathrm{La}_{(1-x)} \mathrm{A}^{\prime} \times \mathrm{MnO}_{3}$ and $\mathrm{La}_{(1-}$ ${ }_{x} \mathrm{~A}_{\mathrm{x}} \mathrm{FeO}_{3}$, with $\mathrm{A}^{\prime}=\mathrm{Ce}, \mathrm{Sr}$ and $\mathrm{x}=0,0.1,0.2$, either pure or doped with noble metals $(0.5$ wt\% Pt or Pd), were prepared in nano-powder form by flame pyrolysis. All the catalysts were tested for the catalytic flameless combustion of methane, monitoring the activity by on-line mass spectrometry. The catalysts were then progressively deactivated in operando with a new procedure, consisting of repeated injection of some doses of tetrahydrothiophene (THT), usually employed as odorant in the natural gas grid, with continuous analysis of the transient response of the catalyst. The activity tests were then repeated on the poisoned catalyst. Different regenerative treatments were also tried, either in oxidising or reducing atmosphere.

Among the unsubstituted samples, higher activity and better resistance to poisoning have been observed in general with manganites with respect to the corresponding formulations containing $\mathrm{Co}$ or $\mathrm{Fe}$ at the B-site. The worst catalyst showed $\mathrm{LaFeO}_{3}$, from both the points of view of activity and of resistance to sulphur

\footnotetext{
* Corresponding author: fax +39-02-50314300, e-mail ilenia.rossetti@unimi.it
} 
poisoning. $\mathrm{La}_{0,9} \mathrm{Sr}_{0,1} \mathrm{MnO}_{3}$ showed, the best results, exhibiting very high activity and good resistance even after the addition of up to $8.4 \mathrm{mg}$ of THT per $\mathrm{g}$ of catalyst. Interesting results were attained also by adding $\mathrm{Sr}$ to Co-based perovskites. Sr showed a first action by forcing $\mathrm{Mn}$ or $\mathrm{Co}$ in their highest oxidation state, but, in addition, it could also act as a sulphur guard, likely forming stable sulphates due to its basicity. Among noble metals, Pt doping proved beneficial in improving the activity of both the fresh and the poisoned catalyst.

Keywords: Methane, catalytic combustion; Sulphur poisoning; Perovskite-like catalysts.

\section{1 - INTRODUCTION}

The catalytic flameless combustion (CFC) of methane outperforms conventional flame combustion because of lower emission of pollutants $\left(\mathrm{HC}, \mathrm{CO}\right.$ and $\left.\mathrm{NO}_{\mathrm{x}}\right)$ and high thermal efficiency. The catalysts traditionally used for CFC are mainly based on supported noble metals, such as $\mathrm{Pd}$ and $\mathrm{Pt}$, which ensure high activity, however accompanied by some drawbacks, due to high cost and poor thermal and chemical stability. La-based catalysts with $\mathrm{ABO}_{3}$ perovskite-like structure [1-4] have been proposed as a valid alternative for the present application. Indeed, perovskite catalysts combine low cost, thermo-chemical stability at high operating temperature and satisfactory catalytic activity [5-8]. In spite of this, there are still some open questions, especially regarding their resistance to sulphur poisoning when used for the CFC of methane. Indeed, the poisoning mechanism of perovskite-like catalysts has not been completely understood and only a few papers deal with this very important topic.

The deactivation mechanism due to exposure to $\mathrm{SO}_{2}$ has been investigated by means of complementary techniques. After $\mathrm{SO}_{2}$ adsorption, unstable surface species 
form, which promptly react with activated oxygen to form sulphates, sulphites and/or sulphides, depending on temperature and catalyst formulation [5,9-12]. The migration of these species from the surface to the bulk has been also observed [1]. Due to its basicity, lanthanum oxide is prone to interact with $\mathrm{SO}_{2}$ forming the corresponding sulphate, whereas no evidence of cobalt sulphate formation was found when treating $\mathrm{LaCoO}_{3}$ with $\mathrm{SO}_{2}[1]$. Depending on the extent of poisoning, the complete destruction of the active phase has been sometimes reached, with formation of segregated B-ion oxide and lanthanum sulphate. The conversion of methane and the resistance of the catalyst to sulphur poisoning have been studied with various combinations of A- and Bsite metals and by adding $\mathrm{MgO}$ as promoter $[5,10,11,13]$. However, though the latter option seems to guarantee a sufficient resistance to poisoning, the promoter essentially acts as a shield, forming stable sulphates and hence competing with the active phase for $\mathrm{SO}_{2}$ adsorption. Its protective action is of course time-limited by its consumption.

Based on the above summarised topics, S-poisoning begins with $\mathrm{SO}_{2}$ adsorption on oxygen vacancies and it is essentially a surface-based mechanism. Therefore, catalyst nanostructuring can deeply affect the resistance towards S-containing impurities. In the recent past, attention has been devoted to catalyst nanostructuring, aiming at obtaining high surface area and defectivity, which should enhance oxygen mobility through the lattice and ensure good catalytic activity. To this purpose, we set up and optimised a flame-pyrolysis (FP) apparatus for the one-step synthesis of perovskitic mixed oxides. It is based on a specially designed burner fed with oxygen and an organic solution of the precursors, the solvent acting as fuel for the flame. FP-synthesized perovskites, showed good phase purity, along with nanometer-size particles and hence very high surface area (sometimes in excess of $100 \mathrm{~m}^{2} / \mathrm{g}$ ) [2-4]. In addition, the high temperature of the flame in principle should also ensure thermal stability. 
In the present work we prepared a set of samples by $F P$, namely $\mathrm{La}_{(1-x)} \mathrm{A}_{\times}^{\prime} \mathrm{BO}_{3}$, with $A^{\prime}=\mathrm{Ce}, \mathrm{Sr}, \mathrm{B}=\mathrm{Mn}, \mathrm{Co}, \mathrm{Fe}$ and $\mathrm{x}=0,0.1,0.2$, either pure or doped with noble metals $(\mathrm{Pt}$ or Pd). The catalysts were tested for the CFC of methane, monitoring the activity by online mass spectrometry. The effect of sulphur poisoning was then investigated "in operando", by monitoring the catalyst transient response during pulsed injection of tetrahydrothiophene (THT). This represents a new testing procedure with respect to those reported in the literature, which mainly repeat standard activity tests after exposure to $\mathrm{SO}_{2}$. The effect of catalyst composition, as well as of nanostructuring, on activity and stability has been investigated.

\section{2 - EXPERIMENTAL}

\section{1 - Samples preparation}

All the precursors solutions were prepared by dissolving in propionic acid (Aldrich, pur. 97\%) salts of the selected metals: $\mathrm{La}\left(\mathrm{CH}_{3} \mathrm{COO}\right)_{3} \cdot 2 \mathrm{H}_{2} \mathrm{O}$ (Aldrich, pur. 99.9\%), $\mathrm{Mn}\left(\mathrm{CH}_{3} \mathrm{COO}\right)_{2} \cdot 4 \mathrm{H}_{2} \mathrm{O}$ (Aldrich, pur. 99.9\%), $\mathrm{Fe}(\mathrm{AcAc})_{3}$ (Aldrich, pur. 97\%, AcAc $=$ acetylacetonate), $\mathrm{Co}\left(\mathrm{CH}_{3} \mathrm{COO}\right)_{2} \cdot 4 \mathrm{H}_{2} \mathrm{O}$ (Fluka, pur. $\left.99 \%\right), \operatorname{Sr}\left(\mathrm{CH}_{3} \mathrm{COO}\right)_{2}$ (Aldrich, pur. 99\%), $\mathrm{Ce}\left(\mathrm{CH}_{3} \mathrm{COO}\right)_{3}$ (Aldrich, pur. 99.9\%), $\mathrm{Pd}\left(\mathrm{CH}_{3} \mathrm{COO}\right)_{2}$ (Fluka, $\left.\mathrm{Pd} 47 \mathrm{wt} \%\right), \mathrm{Pt}(\mathrm{AcAc})_{2}$ (Aldrich, pur. 97\%) in the desired ratio and metal concentration.

The FP apparatus has been described in detail elsewhere [2]. Briefly, it consists of a capillary tube (inner diameter $0.6 \mathrm{~mm}$ ) ending in the centre of a vertical nozzle and connected with a syringe pump (Harvard, mod. 975), feeding the solution of the mixed oxide precursors. The nozzle was co-fed with oxygen (SIAD, purity $>99.95 \%$, flow rate 5 $\mathrm{L} / \mathrm{min}$ ), acting both as oxidant and as dispersing agent, able to form micro-droplets of solution. The main flame is ignited and supported by a ring of twelve premixed $\mathrm{O}_{2}+\mathrm{CH}_{4}$ 
(flow rates $1 \mathrm{~L} / \mathrm{min}$ and $0.5 \mathrm{~L} / \mathrm{min}$, respectively) flamelets. Gas flow rate was regulated by MKS (mod. 1259C) mass flow meters, controlled by a MKS (mod. 247C) control unit. The synthesized nano-particles were collected by means of a $10 \mathrm{kV}$ electrostatic precipitator [14].

\subsection{Catalyst characterisation}

The structure of the prepared lanthanum perovskites was determined by X-ray powder diffractometry on a Philips PW3020 diffractometer. The patterns obtained were compared with literature data for phase recognition [15]. The surface area of the synthesized powders was measured by $\mathrm{N}_{2}$ adsorption/desorption at $77 \mathrm{~K}$ on a Micromeritics ASAP2010 apparatus, after outgassing at $300^{\circ} \mathrm{C}$ overnight. Scanning electron miscoscopy (SEM) analysis was carried out on a LEICA LEO 1420 instrument. The main properties of the prepared catalysts are summarised in Table 1.

\section{3 - Catalytic activity testing}

Catalytic activity tests were carried out by means of a continuous quartz tubular reactor on ca. $0.15 \mathrm{~g}$ of catalyst, pelletized, ground and sieved to $0.15-0.25 \mathrm{~mm}$ particles. Prior to each run, the catalyst was activated in flowing air $\left(20 \mathrm{~cm}^{3} / \mathrm{min}\right)$, while increasing temperature by $10^{\circ} \mathrm{C} / \mathrm{min}$ up to $600^{\circ} \mathrm{C}$, then kept for $1 \mathrm{~h}$. The activity tests were carried out by feeding a mixture composed of $0.34 \%$ vol. $\mathrm{CH}_{4}, 33.3 \%$ vol. air, $\mathrm{He}$ balance, while increasing temperature by $10^{\circ} \mathrm{C} / \mathrm{min}$ from $200^{\circ} \mathrm{C}$ up to $600^{\circ} \mathrm{C}$. Gas flow rate was regulated by means of mass flowmeters (Brooks Instruments, mod. 5850) governed by a control unit (Brooks, mod. 0154). The total gas flow rate was $30 \mathrm{ml} / \mathrm{min}$. 
The outcoming gas was analysed in line by means of a quadrupolar mass spectrometer (MKS, PPT Residual Gas Analyzer), selecting proper mass fragments.

Catalyst poisoning was done in the same apparatus at $450^{\circ} \mathrm{C}$ by injecting 4 doses of $0.15 \mathrm{mg}$ of tetrahydrothiophene (THT, Fluka, pur. $>97 \%$ ) per $1 \mathrm{~g}$ of catalyst, each group of four injections being defined as cycle (corresponding to $0.6 \mathrm{mg}$ THT per $\mathrm{g}$ of catalyst). The catalytic activity was monitored "in operando" during poisoning, by continuously analysing the relevant mass fragments $\left(\mathrm{CH}_{4}, \mathrm{O}_{2}, \mathrm{THT}, \mathrm{SO}_{2}, \mathrm{SO}_{3}, \mathrm{CO}\right.$, $\mathrm{CO}_{2}, \mathrm{H}_{2} \mathrm{O}$ ) and plotting them as partial pressure versus time. The data have been elaborated by calculating the slope of some descriptive lines, indicating the transient response of the catalyst during poisoning, as better detailed in paragraph 3.4. The standard activity test was then repeated after each poisoning cycle. In some cases the amount of poison was increased, after the standard four cycles, until a decrease in conversion was observed. In such cases, "forced" poisoning cycles were used to observe any effect for some very resistant catalysts. Anyway, the total amount of THT injected has been specified in the text (vide infra).

Catalyst regeneration was attempted first by heating in air at $600^{\circ} \mathrm{C}$ for $1 \mathrm{~h}$. A second procedure was based on hydrogen treatment at $500^{\circ} \mathrm{C}$ followed by reoxidation in air at $600^{\circ} \mathrm{C}$. After each treatment activity was checked following the standard procedure.

\section{3 - RESULTS AND DISCUSSION}

All the present catalysts were characterised by high phase purity, since no reflection of extraneous phases has been ever observed for the fresh samples, even in the case of samples doping. This indicates dopant incorporation into the framework or at least very high dispersion as small aggregates, whose size was lower than the 
detection limit of the XRD technique. Peak broadening has been observed for every sample due to the small particles size. Sometimes a bi-modal crystal-size distribution has been observed. BET surface area ranged between $43 \mathrm{~m}^{2} / \mathrm{g}$ for $\mathrm{LaCoO}_{3}$ to $70 \mathrm{~m}^{2} / \mathrm{g}$ for $\mathrm{La}_{0.8} \mathrm{Sr}_{0.2} \mathrm{MnO}_{3}$, due to the flash calcination characterising the FP technique, which limits any deep sintering of the powder. No significant correlation was found between surface area and the nature, or the concentration of the various components. The particle size, determined by SEM analysis, was rather uniform and its mean value ranged between 20 and 50nm.

All the catalysts exhibited a very high activity. Indeed, under the adopted reaction conditions full methane conversion was attained below $600^{\circ} \mathrm{C}$ and carbon dioxide + water were the only detected products. Mass spectrometric data showed sometimes a small drift of the baseline, which led to uncertain determination of $T_{0}$, i.e. the temperature at which methane conversion started. Hence, the same activity tests were repeated while analysing the effluent gas by gas-chromatography, in order to check data accuracy. The results were comparable within $\pm 10^{\circ} \mathrm{C}$.

Tetrahydrothiophene (THT) has been selected as poison due to its wide use as odorising agent in the methane distribution grid (where its concentration is ca. $8 \mathrm{ppmv}$ ). The common poison used in the literature for poisoning tests is $\mathrm{SO}_{2}$, because many papers dealing with this topic focus on catalytic mufflers, where exhaust combustion gases are the feeding mixture of the catalytic reactor (muffler). In the present case, we concentrated on the use of odorised methane as feed for catalytic combustors and hence we took into consideration the decomposition mechanism of the S-containing species under operating conditions as near as possible to the operating ones. It should be underlined that this is relevant not only to centralized power generation, but, most of all, to distributed micro-generation, where the natural gas grid provides the feed without the possibility of very efficient pretreatment. 
A preliminary set of experiments allowed concluding that THT instantly oxidised to $\mathrm{SO}_{2}, \mathrm{CO}_{2}$ and $\mathrm{H}_{2} \mathrm{O}$ in the presence of the catalyst at $450^{\circ} \mathrm{C}$. This temperature has been selected because most samples exhibit the highest reaction rate around this value and the conversion curve is very steep, so to magnify the effect of poisoning. Depending on catalyst composition, the $\mathrm{SO}_{2}$ forming upon THT oxidation was immediately released or retained in the form of different chemisorbed, sulphite or sulphate species. However, any further investigation to discriminate the nature of the sulphur-containing surface or bulk species forming upon poisoning is beyond the scope of the present work. For this point reference has been made to literature data $[1,9,10,12,13]$

\section{1 - Effect of the nature of B metal on activity and resistance to sulphur poisoning}

The activity data collected on the fresh samples are reported in Fig. 1 and the $T_{0}$ and $T_{50}$ values $\left(T_{50}=\right.$ temperature at which $50 \%$ conversion of methane is achieved) are summarised in Table 2. Data show that $\mathrm{LaMnO}_{3}$ and $\mathrm{LaCoO}_{3}$ were the most active catalysts, while $\mathrm{LaFeO}_{3}$ was the less performing one, in spite of its higher lowtemperature activity through the suprafacial mechanism (Fig.1), as previously observed $[6,7,16-18]$.

The residual activity of the undoped $\mathrm{LaBO}_{3}$ catalysts after sulphur poisoning is shown in Table 2 and in Fig.2. $\mathrm{LaMnO}_{3}$ showed the highest resistance to sulphur poisoning. Indeed, after the injection of $2.4 \mathrm{mg}$ of THT per gram of catalyst (4 cycles) it lost ca. 10 points\% of the original conversion. $\mathrm{LaCoO}_{3}$ gave less satisfactory results, since after the same 4 cycles it lost ca. 17 points\% of the original conversion, while the worst sample was $\mathrm{LaFeO}_{3}$, loosing more than 18 points\% (Fig.2). 
The extent of $\mathrm{CO}_{2}$ adsorption on $\mathrm{LaBO}_{3}(\mathrm{~B}=\mathrm{Cr}, \mathrm{Co}, \mathrm{Fe})$ was studied over a wide temperature range by Tejuca et al. [19-21], as a measure of surface basicity and hence as a mean to understand the surface interaction with $\mathrm{SO}_{2}$, when competing with the $\mathrm{CO}_{2}$ forming during the reaction. The $\mathrm{CO}_{2}$ coverage followed the order $\mathrm{LaCrO}_{3}>\mathrm{LaFeO}_{3}>\mathrm{LaCoO}_{3}$. The coverage of $\mathrm{LaMnO}_{3}$ is expected to be intermediate between $\mathrm{LaCrO}_{3}$ and $\mathrm{LaFeO}_{3}$, reflecting a scale of increasing surface basicity $\mathrm{Co}<\mathrm{Fe}<\mathrm{Mn}$. Thus, in principle, $\mathrm{LaMnO}_{3}$ should adsorb $\mathrm{SO}_{2}$ more promptly, leading to fast deactivation. However, there is a competitive adsorption between $\mathrm{CO}_{2}$ and $\mathrm{SO}_{2}$, as already suggested elsewhere [10]. When considering different mass fragments one may notice a more or less delayed $\mathrm{CO}_{2}$ release with respect to $\mathrm{CH}_{4}$ consumption. This is much more evident for Mn-based $\left(\mathrm{ca} .70^{\circ} \mathrm{C}\right.$ ) samples than for Co-containing ones (ca. $10^{\circ} \mathrm{C}$ ). Hence, it can be supposed that $\mathrm{CO}_{2}$ reversibly covers the surface of $\mathrm{LaMnO}_{3}$ so inhibiting $\mathrm{SO}_{2}$ adsorption.

Different poisoning mechanisms have been proposed and reviewed [9], as summarised in the introduction. $\mathrm{SO}_{2}$ can form complexes with all the presently investigated metal ions through acid-base interaction, being able to act both as Lewis acid or base. Poisoning through adsorption can be considered reversible when the original activity is restored with elapsing time without changing the operating conditions. By contrast, the adsorbed $\mathrm{SO}_{2}$ can react with oxygen forming surface sulphites or sulphates, which are stable below their decomposition temperature. Once formed, the reaction can go on in depth following a shell-progressive pathway as discussed elsewhere [1,22].

When poisoning is "limited" to surface adsorption, it should entail low damage to catalytic activity for the present application. Indeed, most of the previously reported investigations deal with three way catalysts and with the $\mathrm{CO}$ oxidation reaction, which occurs via oxygen and $\mathrm{CO}$ chemisorption. $\mathrm{SO}_{2}$ poisoning is believed to highly depress 
activity in that case since its adsorption competes with the reactants for the active sites. In the present application, however, $\mathrm{CH}_{4}$ does not adsorb on the surface and the high temperature reactivity is based on oxygen transfer through the bulk phase. Hence, we would expect a decrease of the suprafacial activity (if relevant), accompanied by a less efficient intrafacial reactivity, due to a decrease of concentration of the available surface sites responsible for oxygen release from the bulk and restoration through a Mars van Krevelen mechanism. This activity depression should be evident until the decomposition temperature of sulphites and sulphates is reached (regeneration). However, if the perovskitic phase is progressively eroded with formation of sulphates, the crystal cell parameters should change, leading to different oxygen mobility, affecting more deeply the catalytic activity. Furthermore, Zhu et al. [1] investigated the poisoning mechanism of $\mathrm{LaCoO}_{3}$ by $\mathrm{SO}_{2}$. They observed sulphate species only on the surface, while a mixture of $\mathrm{La}($ oxi)sulphates and sulphites $+\mathrm{CoO}$ has been found in the bulk phase, with destruction of the perovskitic lattice.

Lowell et al. [23] collected and discussed data on decomposition of sulphates and sulphites of 46 elements. The most relevant data for our scope are summarised in Table 3. Sulphites of $\mathrm{Co}, \mathrm{Mn}, \mathrm{Fe}$ and La disproportionate and decompose to the oxide when heated in an inert atmosphere. According to the data reported in Table 3, under the selected poisoning conditions we would not expect the presence of stable sulphites, but, in case, only of sulphates. The regeneration treatment in air here proposed is not sufficient to allow sulphate decomposition. However, a reducing treatment can partly overcome the problem. Reduction in flowing $\mathrm{H}_{2}$ has been carried out under conditions which do not irreversibly reduce the perovskitic phase (based on preliminary TPR-TPO experiments, not reported), but in principle it should be sufficient to partially reduce sulphates, then allowing their thermal decomposition. Of course, before catalytic testing of the regenerated sample, reoxidation is needed. An advantage of this regeneration 
cycle is the possibility to exploit it in situ, at difference with different procedures described elsewhere $[5,10,11]$. Furthermore, by analysing the effluent gases during the regeneration, we can derive some indication on the species present on the catalyst surface.

During the activity tests following each poisoning cycle the $\mathrm{SO}_{\mathrm{x}}$ fragments have been monitored and desorption peaks were observed in several cases. However, the temperature of these desorption peaks did not correspond to the temperature of sulphate decomposition. A better correspondence has been observed in most cases with the temperature of sulphite decomposition [21]. Indeed, very small $\mathrm{SO}_{2}$ peaks appeared between 400 and $550^{\circ} \mathrm{C}$. However, even in case of $\mathrm{SO}_{2}$ desorption, a negligible increase of methane conversion was observed, indicating that an irreversible deactivation occurred. Some activity recovery has been achieved by $\mathrm{H}_{2}$ treatment at $500^{\circ} \mathrm{C}$, as observed also in [24] for a different catalytic system, followed by oxidation in air at $600^{\circ} \mathrm{C}$ in order to regenerate the oxidised sites. However, the initial activity has never been recovered once severe deactivation occurred.

\section{2 - Effect of partial substitution at A site.}

Doping at $\mathrm{A}$ position was investigated on $\mathrm{LaCoO}_{3}$ and $\mathrm{LaMnO}_{3}$ samples, which showed the most promising from both the points of view of activity and resistance to sulphur poisoning. Catalytic activity data for methane combustion are reported in Table 2 and in Fig.3. At difference with what reported elsewhere [8], doping at A position did not bring about very significant effects on catalytic activity, i.e. $T_{50}$ were similar for differently substituted samples, at least within the detection limits of the detection apparatus (vide supra). This is also due to the high catalytic activity of the whole set of samples, which flattens small differences in conversion. 
$10 \% \mathrm{Sr}$ substitution moderately enhanced the activity of Mn-based perovskite and slightly decreased the activity of Co-based one. Further Sr addition in Mn-based perovskite did not show any positive effect on activity. By contrast, $\mathrm{Ce}^{4+}$-containing samples may show a $\mathrm{La}_{1-\mathrm{x}} \mathrm{Ce}_{y} \varnothing_{x-y} \mathrm{MeO}_{3}$ formula, $\varnothing$ being a cationic vacancy formed upon $\mathrm{CeO}_{2}$ segregation in extraframework position. In our Ce-substituted catalysts $\mathrm{y} \cong \mathrm{x}$, since the reflections of the $\mathrm{CeO}_{2}$ phase were never detected by XRD. In this case, $\mathrm{Ce}^{4+}$ in framework position can force an equivalent portion of the trivalent $\mathrm{B}$ metal ion to reduce to a formally divalent oxidation state. This usually stabilises the catalyst in reducing atmosphere and makes the formation of oxygen vacancies uneasy. However, Ce can act as oxygen buffer and its own $4+/ 3+$ redox cycle, occurring at temperature near to that of the B metal, can give a contribution to the whole catalytic reaction. By contrast, Sr-doping should lead to the increase of oxygen vacancies concentration, as well as to the increase of the $B$ metal ion formal oxidation state, depending on its nature. The former effect is more likely with $\mathrm{B}=\mathrm{Co}$, though Nakamura et al. $[25,26]$ showed that in some cases oxygen vacancies did not form up to $x=0.4$ with $B=M n$.

All samples lost part of their initial activity for methane combustion after poisoning. However, the degree of activity loss varied considerably with composition as depicted in Fig.4 and Table 2. $\mathrm{La}_{0.8} \mathrm{Sr}_{0.2} \mathrm{MnO}_{3}$ showed the highest resistance to sulphur poisoning. Indeed, it lost only 5 points\% of its initial conversion after injection of $2.4 \mathrm{mg}$ of THT and 7 points\% after injection of $8.4 \mathrm{mg}$ of THT. In general, $\mathrm{Sr}$ substitution improved the resistance to sulphur poisoning for both Co- and Mn-based perovskites, the resistance increasing with increasing the substitution degree. As pointed out above, Sr-doping may push the B site cation to its highest valence state and/or increase the number of oxygen ion vacancies, so increasing the mobility of lattice oxygen. The acid character of a metal ion increases with its oxidation state and therefore the $\mathrm{SO}_{2}$ bonding with the surface might be weakened. Furthermore, Sr can also act as a sulphur guard, 
since it can form stable sulphates, capturing part of the poisoning agent. On the other hand, $\mathrm{Ce}^{4+}$-substitution showed a different effect. In the case of Co-based perovskites it led to improved resistance to poisoning, while the opposite effect was observed for LaMn perovskites. Introduction of $\mathrm{Ce}^{+4}$ brings about a partial reduction of the $\mathrm{B}$ ion, i.e. to less acidic $\mathrm{B}$ ions. The same holds for the redox couple $\mathrm{Co}^{3+/ 2+}$, though the effect is much less evident in terms of acidity. This could be the reason why $\mathrm{La}_{0.9} \mathrm{Ce}_{0.1} \mathrm{MnO}_{3}$ has worse resistance to poisoning than the unsubstituted $\mathrm{LaMnO}_{3}$ sample.

\section{3 - Effect of noble metals addition}

Noble metal doping was investigated on $\mathrm{LaCoO}_{3}$ and $\mathrm{LaMnO}_{3}$ samples. Indeed, it was reported that catalytic activity of perovskites can be increased through the addition of small amounts of noble metals $[19,27,28]$. This is confirmed by the present data (Table 2 and Fig.5) for Co-based perovskites doped with either Pt or Pd. By contrast, for Mn-based catalysts Pt doping led to an activity improvement, while Pd doping decreased methane conversion. Furthermore, as for undoped samples, catalytic activity for Mn-based perovskite was generally a bit higher than for Co-based.

The reason of the different behaviour of Pt- and Pd-doped samples is not yet fully clear. One hypothesis can be that $\mathrm{Pd}$ can be better inserted into the $\mathrm{LaMnO}_{3}$ lattice, so modifying the oxygen mobility. However, at the moment we do not have yet evidence of this by elaboration of XRD diffractograms, the latter being very complex due to the small amount of dopant and, most of all, to the nanometric particle size of the catalyst. In addition, temperature programmed reduction showed different behaviour for $\mathrm{Mn}$ and Co based perovskites doped with noble metals. Indeed, it seems that both $\mathrm{Pt}$ and $\mathrm{Pd}$ addition to $\mathrm{LaCoO}_{3}$ increase sample reducibility, while for $\mathrm{LaMnO}_{3}$, the reduction temperature is only a bit lower for the Pt-doped sample, but higher for the Pd-doped one, with respect to pure $\mathrm{LaMnO}_{3}$. 
All samples lost part of their initial activity after poisoning, but noble metals addition increased resistance to poisoning, at least after addition of small amounts of THT (Table 2, Fig.6). Among this set of noble metal doped samples $0.5 \% \mathrm{Pt} / \mathrm{LaMnO}_{3}$ showed the highest resistance to sulphur poisoning. Indeed, it lost 6 points $\%$ of initial conversion after injection of $2.4 \mathrm{mg}$ THT and less than 10 after injection of $7.2 \mathrm{mg}$ THT (per $\mathrm{g}$ of catalyst). For Mn-based perovskites the resistance was higher than for Co-based ones, as observed for non-substituted samples (Fig.2). However, the most evident effect has been observed after the first injections, suggesting that noble metals protect the surface sites by reacting more promptly with sulphur [13], Pt doping being more effective than Pd.

The Pt-doped manganite sample even showed a very small increase of conversion after the first poisoning cycle. This behaviour has been yet observed with different Ptbased catalysts (see e.g. [29]) and explained by a decrease of concentration of small PtO particles, leading to higher activity.

At difference with what reported for all the other samples, catalyst regeneration by $\mathrm{H}_{2}$ treatment showed positive in the case of noble metal doped samples, particularly for Pd-containing catalysts. Indeed, although the activity of the fresh catalyst has never been recovered, some encouraging result has been attained. This supports the shielding effect above hypothesised, since the reducing treatment should reduce the metallic surface. Indeed, at least in the case of $\mathrm{Pd}$-doped samples, $\mathrm{H}_{2} \mathrm{~S}$ release has been detected during the regeneration treatment in $\mathrm{H}_{2}$. This result can be interesting for practical reasons, showing the possibility to partially regenerate the catalyst by in situ treatment.

\section{4 - Transient response during poisoning}


A typical example of catalyst transient response during poisoning is presented in Fig. 7 for $\mathrm{LaCoO}_{3}$. The trend of methane partial pressure vs. time during poisoning has been used to calculate an approximate deactivation rate at $450^{\circ} \mathrm{C}$ for every catalyst. All the patterns have been approximated by straight lines and the corresponding slopes are reported in Table 4. The data there reported should be considered as an average poisoning rate. Due to the different response of the present catalysts, an "initial" deactivation rate is also reported in Table 5. The latter parameter represents the slope of the tangent to the methane partial pressure vs. time curve at the starting point of the first injection of each cycle. This should give an idea of the curve pattern. Indeed, its value should range from 0 (no deactivation) to infinite (step response). Furthermore, if the initial rate is higher that the average value, the catalyst tend to stabilize and vice versa.

From Tables 4 and 5 one can see that $\mathrm{LaFeO}_{3}$ has the highest initial deactivation rate in most cycles. Exception is the first cycle, where this parameter is higher for $\mathrm{Mn}$ based perovskite doped with Sr. However, $\mathrm{La}_{0.9} \mathrm{Sr}_{0.1} \mathrm{MnO}_{3}$ and $\mathrm{La}_{0.8} \mathrm{Sr}_{0.2} \mathrm{MnO}_{3}$ have average deactivation rate smaller than other catalysts. This means that they have a rapid response followed by equilibration to a plateau. An opposite behavior can be observed for $\mathrm{LaMnO}_{3}$, which showed the lowest initial rate. Average data of four cycles show that $\mathrm{La}_{0.9} \mathrm{Ce}_{0.1} \mathrm{MnO}_{3}$ was characterised by the highest average poisoning rate, while $\mathrm{La}_{0.9} \mathrm{Ce}_{0.1} \mathrm{CoO}_{3}$ showed the lowest one.

The above reported data should be considered as a semi-quantitative parameter to check the readiness of catalyst response. Best resistance can be represented by a low overall loss of activity, a high initial deactivation rate followed by a low average decrease of activity. 


\section{4 - CONCLUSIONS}

All the present perovskite-like catalysts prepared by FP showed good activity for the CFC of methane, the best results being achieved with $\mathrm{La}_{0.9} \mathrm{Sr}_{0.1} \mathrm{MnO}_{3}$. Good results have been also obtained by adding ca. 0.5 wt\% Pt to $\mathrm{LaMnO}_{3}$ or $\mathrm{LaCoO}_{3}$, whereas $\mathrm{Pd}$ led to less satisfactory results.

A new in operando procedure to test the resistance to sulphur poisoning has been proposed, based on pulsed injections of THT, a common odorising agent for natural gas. An overview of the activity loss after several THT injections allowed to conclude that: i) the $\mathrm{Mn}$ based lanthanum perovskites are more resistant than the Co and Fe containing formulations; ii) Sr substitution minimises the activity loss, Sr acting as a sulphur guard; iii) Pt addition improves the resistance to poisoning by adsorbing the Scontaining species more promptly than the active phase. In situ regenerative treatments with $\mathrm{H}_{2}$ can partly restore the original activity, in particular in the presence of noble metals. Finally, by monitoring the transient behaviour during THT addition, the readiness of response to poisoning of the various formulations could be highlighted.

\section{REFERENCES}

1. Y.Zhu, R. Tan, J. Feng, S. Ji, L. Cao. Appl. Catal. A 209 (2001) 71

2. G.L. Chiarello, I. Rossetti, L. Forni. J. Catal. 236 (2005) 251

3. G.L. Chiarello, I. Rossetti, L. Forni, P. Lopinto, G. Migliavacca. Appl. Catal. B 72 (2007) 218

4. G.L. Chiarello, I. Rossetti, L. Forni, P. Lopinto, G. Migliavacca. Appl. Catal. B 72 (2007) 227

5. I. Rosso, G. Saracco, V. Specchia, E. Garrone. Appl. Catal D 40 (2003) 195

6. I. Rossetti, I. Forni, Appl. Catal. B: Environmental, 33 (2001) 345.

7. L. Fabbrini, I. Rossetti, L. Forni, Appl. Catal. B: Environmental, 63 (2006) 131. 
8. R. Leanza, I. Rossetti, L. Fabbrini, C. Oliva, L. Forni, Appl. Catal. B: Environmental, $28(2000) 55$.

9. L. Wan in: .G. Tejuca, J.L.G. Fierro (Eds.), Properties and applications of the Perovskite-type oxides, Marcel Dekker, Mew York, 1993, p. 145

10. I. Rosso, E. Garrone, F. Geobaldo, B. Onida, G. Saracco, V. Specchia. Appl. Catal. B 34 (2001) 29.

11. I. Rosso, E. Garrone, F. Geobaldo, B. Onida, G. Saracco, V. Specchia. Appl. Catal. B $30(2001) 61$

12. M. Alifanti, R. Auer, J. Kirchnerova, F. Thyrion, P. Grange, B. Delmon. Appl. Catal. B 41 (2003) 71

13. M.J. Koponen, T. Venäläinen, M. Suvanto, K. Kallinen, T-J.J. Kinnunen, M. Härkönen, T.A. Pakkanen. J. Molec. Catal. A 258 (2006) 246

14. R.A.M. Giacomuzzi, M. Portinari, I. Rossetti, L. Forni, in: A. Corma, F.V. Melo, S. Mendioroz, J.L.G. Fierro (Eds), Study of surface Science and Catalysis, vol. 130, Elsevier, Amsterdam, 2000, p.197

15. Selected Powder Diffraction Data, Miner. DBM (1-40), J.C.P.D.S., Swarthmore, PA, 1974-1992

16. Voorhoeve, R.J.H., J.P. Remeika, P.E. Freeland, T. Mathias, Rera-earth oxides of manganese and cobalt rival platinum for the treatment of carbon monoxide in auto exhaust, Science 177:353 (1972)

17. N. Yamazoe, Y. Teraoka, Catal. Today 8 (1990) 175

18. Arai, H., T. Yamada, K. Eguchi, T. Seiyama, Appl. Catal. 26 (1986) 265

19. M.A. Peña, J.L.G. Fierro, Chem Rev. 101 (2001) 1981

20. L.G. Tejuca, A.T. Bell, V. Cortes, Appl. Surf. Sci. 37 (1989) 353

21. V. Cortes, L.G. Tejuca, A.T. Bell, J. Mater. Sci 24 (1989) 4437 
22. Y. Zhang-Steenwinkel, H.L. Castricum, J. Beckers, E. Eiser, A. Bliek, J. Catal. 221 (2004) 523

23. Lowell P.S., K. Schwitzgebel, T.B. Parsons, K.S. Sladek, Ind. Eng. Chem. Proc. Des. Develop. 10 (1971) 384

24. R. Burch, T.C. Watling, Appl. Catal. B 17 (1998) 131

25. T. Nakamura, M. Misono, Y. Yoneda, J. Catal. 83 (1983) 151

26. T. Nakamura, M. Misono, Y. Yoneda, Bull. Chem. Soc. Jpn 55 (1982) 394

27. H. Tanaka, M. Misono, Curr. Opin. Solid State Mater Sci 5 (2001)

28. M.J. Koponen, M. Suvanto, T.A. Pakkanen, K. Kallinen, T-J.J. Kinnunen, M. Härkönen, Solid State Sci 7 (2005) 7

29. A.K. Neyestanaki, F. Klingstedt, T. Salmi, D.Yu. Murzin, Fuel, 83 (2004) 395. 


\section{TABLES}

Table 1 : Main catalyst properties. SSA = specific surface area $(B E T)$. Particle size determined from SEM analysis

\begin{tabular}{|c|c|c|}
\hline Catalyst & SSA, $\mathrm{m}^{2} / \mathrm{g}$ & Particle size, $\mathrm{nm}$ \\
\hline $\mathrm{LaMnO}_{3}$ & 56 & $35-40$ \\
\hline $\mathrm{LaCoO}_{3}$ & 43 & - \\
\hline $\mathrm{LaFeO}_{3}$ & - & - \\
\hline $\mathrm{La}_{0.9} \mathrm{Sr}_{0.1} \mathrm{MnO}_{3}$ & 51 & $25-35$ \\
\hline $\mathrm{La}_{0.8} \mathrm{Sr}_{0.2} \mathrm{MnO}_{3}$ & 70 & $25-60$ \\
\hline $\mathrm{La}_{0.9} \mathrm{Ce}_{0.1} \mathrm{MnO}_{3}$ & 61 & $30-45$ \\
\hline $\mathrm{La}_{0.9} \mathrm{Sr}_{0.1} \mathrm{CoO}_{3}$ & 52 & $20-60$ \\
\hline $\mathrm{La}_{0.9} \mathrm{Ce}_{0.1} \mathrm{CoO}_{3}$ & 62 & - \\
\hline $0.5 \% \mathrm{Pt} / \mathrm{LaMnO}_{3}$ & 63 & ca. 40 \\
\hline $0.5 \% \mathrm{Pt} / \mathrm{LaCoO}_{3}$ & 58 & ca. 50 \\
\hline $0.5 \% \mathrm{Pd} / \mathrm{LaMnO}_{3}$ & 53 & $30-35$ \\
\hline $0.5 \% \mathrm{Pd} / \mathrm{LaCoO}_{3}$ & 54 & - \\
\hline
\end{tabular}


Table 2: Activity data of fresh and poisoned catalysts (after one and four poisoning cycles, if not specified differently). $\mathrm{T}_{0}=$ temperature at which $\mathrm{CH}_{4}$ conversion started; $\mathrm{T}_{50}=$ temperature of $50 \% \mathrm{CH}_{4}$ conversion; Conv ${ }_{450^{\circ} \mathrm{C}}=\mathrm{CH}_{4} \%$ conversion at $450^{\circ} \mathrm{C}$. Activity data for poisoned and regenerated samples given as $\mathrm{CH}_{4} \%$ conversion at $450^{\circ} \mathrm{C}$.

\begin{tabular}{|c|c|c|c|c|c|c|c|}
\hline \multirow[b]{2}{*}{ Sample } & \multicolumn{3}{|c|}{ Fresh catalyst } & \multicolumn{2}{|c|}{ Poisoned catalyst } & \multicolumn{2}{|c|}{ Regenerated } \\
\hline & $\mathrm{T}_{0}$ & $T_{50}$ & $\begin{array}{l}\text { Conv } \\
450^{\circ} \mathrm{C}\end{array}$ & 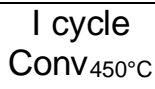 & $\begin{array}{l}\text { Last cycle } \\
\text { Conv } 450^{\circ} \mathrm{C}\end{array}$ & Air & $\mathrm{H}_{2}$ \\
\hline $\mathrm{LaCoO}_{3}$ & 250 & 449 & 52.3 & 43.0 & 35.7 & 32.7 & 30.4 \\
\hline $\mathrm{La}_{0.9} \mathrm{Sr}_{0.1} \mathrm{CoO}_{3}$ & 243 & 453 & 48.0 & 46.6 & $44.2^{*}$ & 46.4 & 29.3 \\
\hline $\mathrm{La}_{0.9} \mathrm{Ce}_{0.1} \mathrm{CoO}_{3}$ & 262 & 447 & 52.5 & 53.0 & 44.4 & 43.7 & 35.5 \\
\hline $\mathrm{LaMnO}_{3}$ & 262 & 435 & 59.4 & 54.1 & 49.9 & 28.0 & 38.6 \\
\hline $\mathrm{La}_{0.9} \mathrm{Ce}_{0.1} \mathrm{MnO}_{3}$ & 252 & 433 & 59.5 & 55.5 & 45.7 & 51.4 & 39.1 \\
\hline $\mathrm{La}_{0.9} \mathrm{Sr}_{0.1} \mathrm{MnO}_{3}$ & 270 & 419 & 70.0 & 66.5 & $63.6^{\star \star \star}$ & 56.1 & 1 \\
\hline $\mathrm{La}_{0.8} \mathrm{Sr}_{0.2} \mathrm{MnO}_{3}$ & 260 & 434 & 60.0 & 67.5 & $53.2^{\star \star \star}$ & 44.4 & 1 \\
\hline $\mathrm{LaFeO}_{3}$ & 273 & 495 & 29.4 & 17.3 & 10.6 & 17.1 & 16.1 \\
\hline $0.5 \% \mathrm{Pt} / \mathrm{LaCoO}_{3}$ & 262 & 435 & 60.4 & 54.2 & $40.3^{*}$ & 39.0 & 39.9 \\
\hline $0.5 \% \mathrm{Pt} / \mathrm{LaMnO}_{3}$ & 255 & 426 & 64.5 & 67.1 & $54.9^{\star \star}$ & 57.2 & 62.1 \\
\hline $0.5 \% \mathrm{Pd} / \mathrm{LaCoO}_{3}$ & 270 & 441 & 56.7 & 52.6 & $35.4^{*}$ & 31.4 & 37.0 \\
\hline $0.5 \% \mathrm{Pd} / \mathrm{LaMnO}_{3}$ & 262 & 445 & 53.0 & 50.0 & $41.5^{\star}$ & 41.7 & 44.3 \\
\hline
\end{tabular}

* - after $4.8 \mathrm{mg}$ THT per g of catalyst

** - after $7.2 \mathrm{mg}$ THT per g of catalyst

${ }^{* * \star}$ - after $8.4 \mathrm{mg}$ THT per g of catalyst 
Table 3: Synopsis of sulphate and sulphite decomposition temperature [23].

\begin{tabular}{|c|c|c|c|c|}
\hline Element & $\begin{array}{c}\text { Sulphite } \\
\text { decomposition, }{ }^{\circ} \mathrm{C}\end{array}$ & $\begin{array}{c}\text { Dispoportionation } \\
\text { favourable, } 25-800^{\circ} \mathrm{C}\end{array}$ & $\begin{array}{c}\text { Sulphate } \\
\text { decomposition, }{ }^{\circ} \mathrm{C}\end{array}$ & Method \\
\hline $\mathrm{Co}^{+2}$ & 340 & yes & $680-930^{*}$ & $\mathrm{~S}$ \\
\hline $\mathrm{Fe}^{+2}$ & 265 & yes & $603-810^{*}$ & $\mathrm{~F}$ \\
\hline $\mathrm{Fe}^{+3}$ & - & - & $781-810^{* *}$ & $\mathrm{~F}$ \\
\hline $\mathrm{Mn}^{+2}$ & 325 & yes & $880-1100^{*}$ & $\mathrm{~A}$ \\
\hline $\mathrm{La}^{+3}$ & - & - & $890-1096^{* * *}$ & $\mathrm{~A}$ \\
\hline & ${ }^{*}$ - decomposes with oxidation \\
${ }^{* *}$ - decomposes directly to oxide \\
${ }^{* * *}$ - decomposes via oxysulphates \\
F- under flowing inert gas \\
S - static experiment \\
A - sample decomposed in air
\end{tabular}

Table 4: Average deactivation rate $($ Torr $/ \mathrm{min} ; 1$ Torr $=133 \mathrm{~Pa})$ during each poisoning cycle (Fig. 7, angle $\beta$ ).

\begin{tabular}{|c|c|c|c|c|c|c|c|c|c|}
\hline \multirow{2}{*}{ Catalyst } & \multicolumn{9}{|c|}{ Poisoning cycle no. } \\
\hline & I & II & III & IV & V & VI & VII & VIII & IX \\
\hline $\mathrm{LaCoO}_{3}$ & 0.00092 & 0.0034 & 0.0066 & 0.0039 & - & - & - & - & - \\
\hline $\mathrm{LaMnO}_{3}$ & 0.0014 & 0.02 & 0.019 & 0.0016 & - & - & - & - & - \\
\hline $\mathrm{LaFeO}_{3}$ & 0.0037 & 0.00053 & 0.0059 & 0.0018 & - & - & - & - & - \\
\hline $\mathrm{La}_{0.9} \mathrm{Sr}_{0.1} \mathrm{CoO}_{3}$ & 0.00033 & 0.002 & 0.0028 & 0.00192 & 0.0023 & - & - & - & - \\
\hline $\mathrm{La}_{0.9} \mathrm{Ce}_{0.1} \mathrm{CoO}_{3}$ & 0.0032 & 0.0022 & 0.0033 & 0 & - & - & - & - & - \\
\hline $\mathrm{La}_{0.9} \mathrm{Sr}_{0.1} \mathrm{MnO}_{3}$ & 0.0044 & 0.00056 & 0.00052 & 0.0046 & 0.014 & 0.0027 & 0.00044 & 0.0098 & \\
\hline $\mathrm{La}_{0.8} \mathrm{Sr}_{0.2} \mathrm{MnO}_{3}$ & 0.0019 & 0.0021 & 0.00044 & 0.006 & 0.0027 & 0.00045 & 0.0064 & 0.004 & 0.0017 \\
\hline $\mathrm{La}_{0.9} \mathrm{Ce}_{0.1} \mathrm{MnO}_{3}$ & 0.0017 & 0.0029 & 0.0074 & 0.0064 & - & - & - & - & - \\
\hline $0.5 \% \mathrm{Pt} / \mathrm{LaCoO} 3$ & 0.0014 & 0.0018 & 0.0008 & 0.0015 & & & & & \\
\hline $0.5 \% \mathrm{Pt} / \mathrm{LaMnO} 3$ & 0 & 0.0042 & 0.0023 & 0.01 & 0.007 & & & & \\
\hline $0.5 \% \mathrm{Pd} / \mathrm{LaCoO}_{3}$ & 0.0002 & 0.0009 & 0.0012 & 0.002 & 0.005 & & & & \\
\hline $0.5 \% \mathrm{Pd} / \mathrm{LaMnO}_{3}$ & 0.001 & 0.001 & 0.0008 & 0.0007 & 0 & & & & \\
\hline
\end{tabular}


Tab. 5: Initial deactivation rate (Torr/min; 1 Torr $=133 \mathrm{~Pa}$ ) for each poisoning cycle (Fig. 7, angle $\alpha$ ).

\begin{tabular}{|c|c|c|c|c|c|c|c|c|c|}
\hline \multirow{2}{*}{ Catalyst } & \multicolumn{9}{|c|}{ Poisoning cycle no. } \\
\hline & 1 & II & III & IV & $\mathrm{V}$ & $\mathrm{VI}$ & VII & VIII & IX \\
\hline $\mathrm{LaCoO}_{3}$ & 0.039 & 0.086 & 0.034 & 0.043 & - & - & - & - & - \\
\hline $\mathrm{LaMnO}_{3}$ & 0.088 & 0.02 & 0.019 & -0.037 & - & - & - & - & - \\
\hline $\mathrm{LaFeO}_{3}$ & 0.089 & 0.14 & 0.28 & 0.12 & - & - & - & - & - \\
\hline $\mathrm{La}_{0.9} \mathrm{Sr}_{0.1} \mathrm{CoO}_{3}$ & 0.068 & 0.045 & 0.09 & 0.045 & 0.0023 & - & - & - & - \\
\hline $\mathrm{La}_{0.9} \mathrm{Ce}_{0.1} \mathrm{CoO}_{3}$ & 0.056 & 0.015 & 0.11 & 0.07 & - & - & - & - & - \\
\hline $\mathrm{La}_{0.9} \mathrm{Sr}_{0.1} \mathrm{MnO}_{3}$ & 0.11 & 0.054 & 0.06 & 0.09 & 0.014 & 0.136 & 0.136 & 0.01 & \\
\hline $\mathrm{La}_{0.8} \mathrm{Sr}_{0.2} \mathrm{MnO}_{3}$ & 0.24 & 0.067 & 0.138 & 0.067 & 0.087 & 0.059 & 0.044 & 0.004 & 0.002 \\
\hline $\mathrm{La}_{0.9} \mathrm{Ce}_{0.1} \mathrm{MnO}_{3}$ & 0.075 & 0.08 & -0.02 & -0.068 & - & - & - & - & - \\
\hline $0.5 \% \mathrm{Pt} / \mathrm{LaCoO}_{3}$ & 0.089 & 0.14 & 0.1 & 0.18 & & & & & \\
\hline $0.5 \% \mathrm{Pt} / \mathrm{LaMnO}_{3}$ & 0.11 & 0 & 0.06 & 0.22 & 0.045 & & & & \\
\hline $0.5 \% \mathrm{Pd} / \mathrm{LaCoO}_{3}$ & 0.041 & 0.018 & 0.027 & 0.13 & 0.27 & & & & \\
\hline $0.5 \% \mathrm{Pd} / \mathrm{LaMnO}_{3}$ & 0.2 & 0.2 & 0.022 & 0.045 & 0.18 & & & & \\
\hline
\end{tabular}




\section{FIGURE CAPTIONS}

Fig.1: Catalytic activity of undoped, fresh $\mathrm{LaBO}_{3}$ catalysts: $(\boldsymbol{\bullet}) \mathrm{LaFeO}_{3},(\bullet) \mathrm{LaCoO}_{3},(\mathbf{\Lambda})$ $\mathrm{LaMnO}_{3}$

Fig.2: Catalytic activity after sulphur poisoning of (a) $\mathrm{LaMnO}_{3}$, (b) $\mathrm{LaCoO}_{3},(c) \mathrm{LaFeO}_{3}$ : (-) fresh sample, $(\boldsymbol{\Lambda})$ after $1^{\text {st }}$ and $(\bullet) 4^{\text {th }}$ poisoning cycle

Fig.3: Catalytic activity of fresh $\mathrm{La}_{1-x} \mathrm{~A}_{x}{ }^{\prime} \mathrm{BO}_{3 \pm \delta}$ catalysts: (ם) $\mathrm{La}_{0.9} \mathrm{Sr}_{0.1} \mathrm{MnO}_{3 \pm \delta}$, $\mathrm{La}_{0.9} \mathrm{Ce}_{0.1} \mathrm{MnO}_{3 \pm \delta},(\mathbf{\Delta}) \mathrm{La}_{0.8} \mathrm{Sr}_{0.2} \mathrm{MnO}_{3 \pm \delta},(\square) \mathrm{La}_{0.9} \mathrm{Sr}_{0.1} \mathrm{CoO}_{3 \pm \delta},(\mathrm{O}) \mathrm{La}_{0.9} \mathrm{Ce}_{0.1} \mathrm{CoO}_{3 \pm \delta}$.

Fig. 4: Catalytic activity after sulphur poisoning of (a) $\mathrm{La}_{0.8} \mathrm{Sr}_{0.2} \mathrm{MnO}_{3}$; $\mathrm{La}_{0.9} \mathrm{Sr}_{0.1} \mathrm{MnO}_{3}$; (c) $\mathrm{La}_{0.9} \mathrm{Sr}_{0.1} \mathrm{CoO}_{3}$; (d) $\mathrm{La}_{0.9} \mathrm{Ce}_{0.1} \mathrm{MnO}_{3}$; (e) $\mathrm{La}_{0.9} \mathrm{Ce}_{0.1} \mathrm{CoO}_{3}$. Symbols: (-) fresh sample, $(\mathbf{\Delta})$ after $1^{\text {st }}$ and $(\bullet)$ last poisoning cycle. Last cycle means $4^{\text {th }}$ for every catalyst except a) and b), tested after the addition of $8.4 \mathrm{mg} \mathrm{THT}$.

Fig 5: Catalytic activity of fresh $\mathrm{LaBO}_{3}$ catalysts doped with noble metals: (-) $\mathrm{LaCoO}_{3}+0.5 \% \mathrm{Pt},(\mathbf{\Delta}) \mathrm{LaMnO}_{3}+0.5 \% \mathrm{Pt},(\square) \mathrm{LaCoO}_{3}+0.5 \% \mathrm{Pd},(\Delta) \mathrm{LaMnO}_{3}+0.5 \% \mathrm{Pd}$.

Fig 6: Catalytic activity after sulphur poisoning of (a) $0.5 \% \mathrm{Pt}+\mathrm{LaCoO}_{3}$; (b) $0.5 \% \mathrm{Pt}+\mathrm{LaMnO}_{3} ;$ (c) $0.5 \% \mathrm{Pd}+\mathrm{LaCoO}_{3} ;$ (d) $0.5 \% \mathrm{Pd}+\mathrm{LaMnO}_{3}$. Symbols: (-) fresh sample, $(\mathbf{\Delta})$ after $2^{\text {nd }}$ and $(\bullet) 5^{\text {th }}$ poisoning cycle

Fig. 7: Transient response for $\mathrm{LaCoO}_{3}$. The values of $\alpha$ and $\beta$ (Torr/min, 1 Torr $=133$ Pa) are reported in Tables 4 and 5 . 
Fig. 1

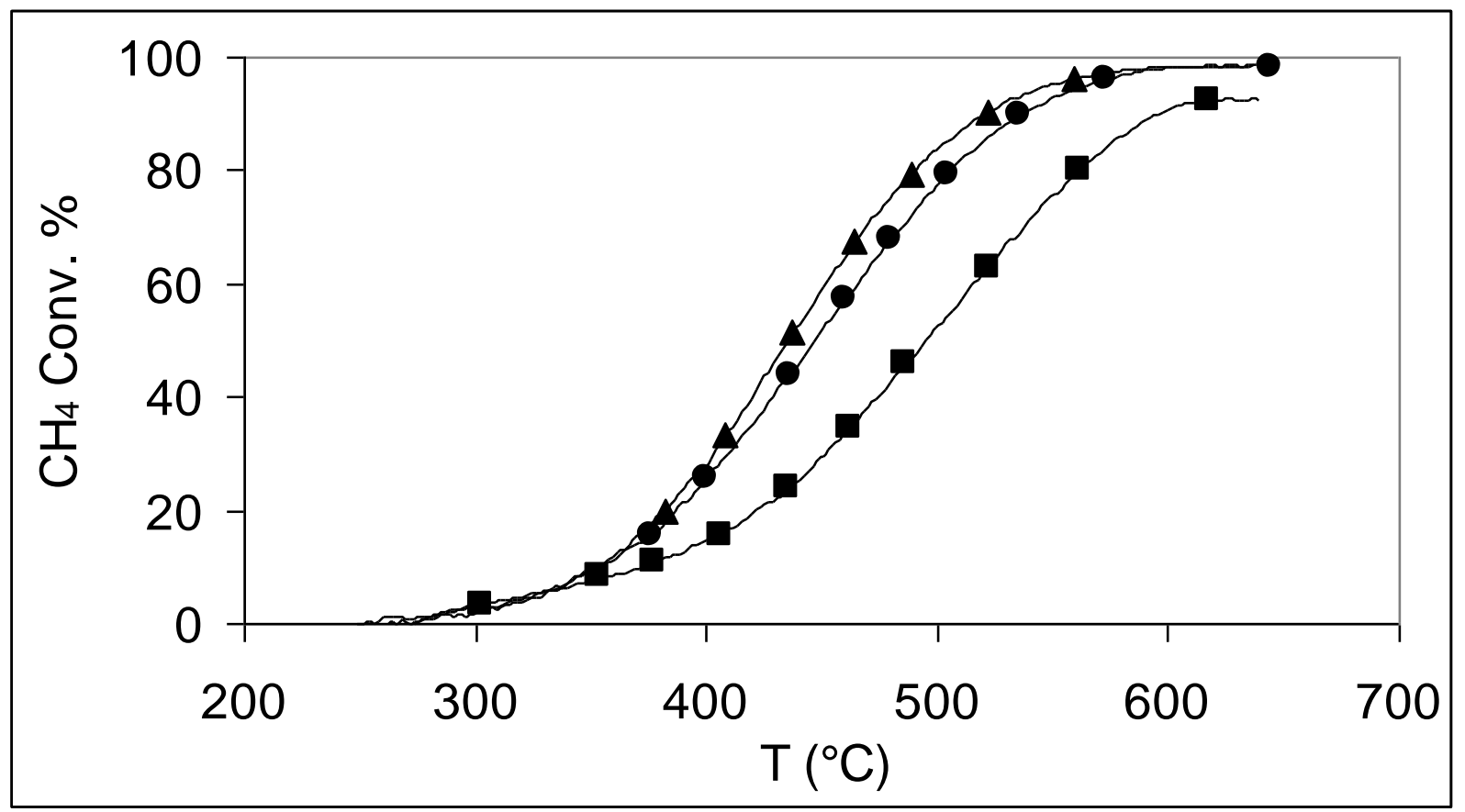

Fig 2.

(a)

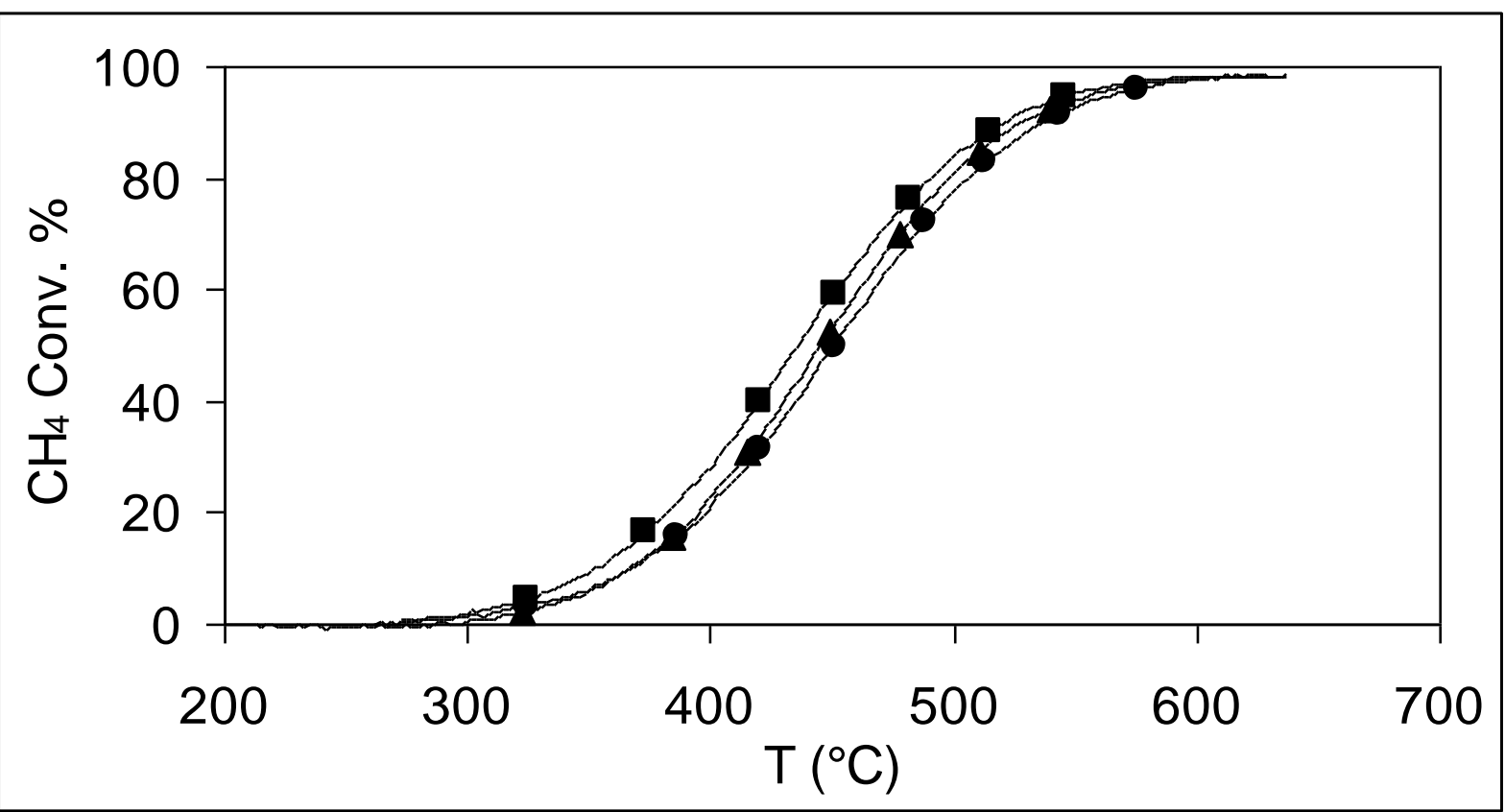


(b)

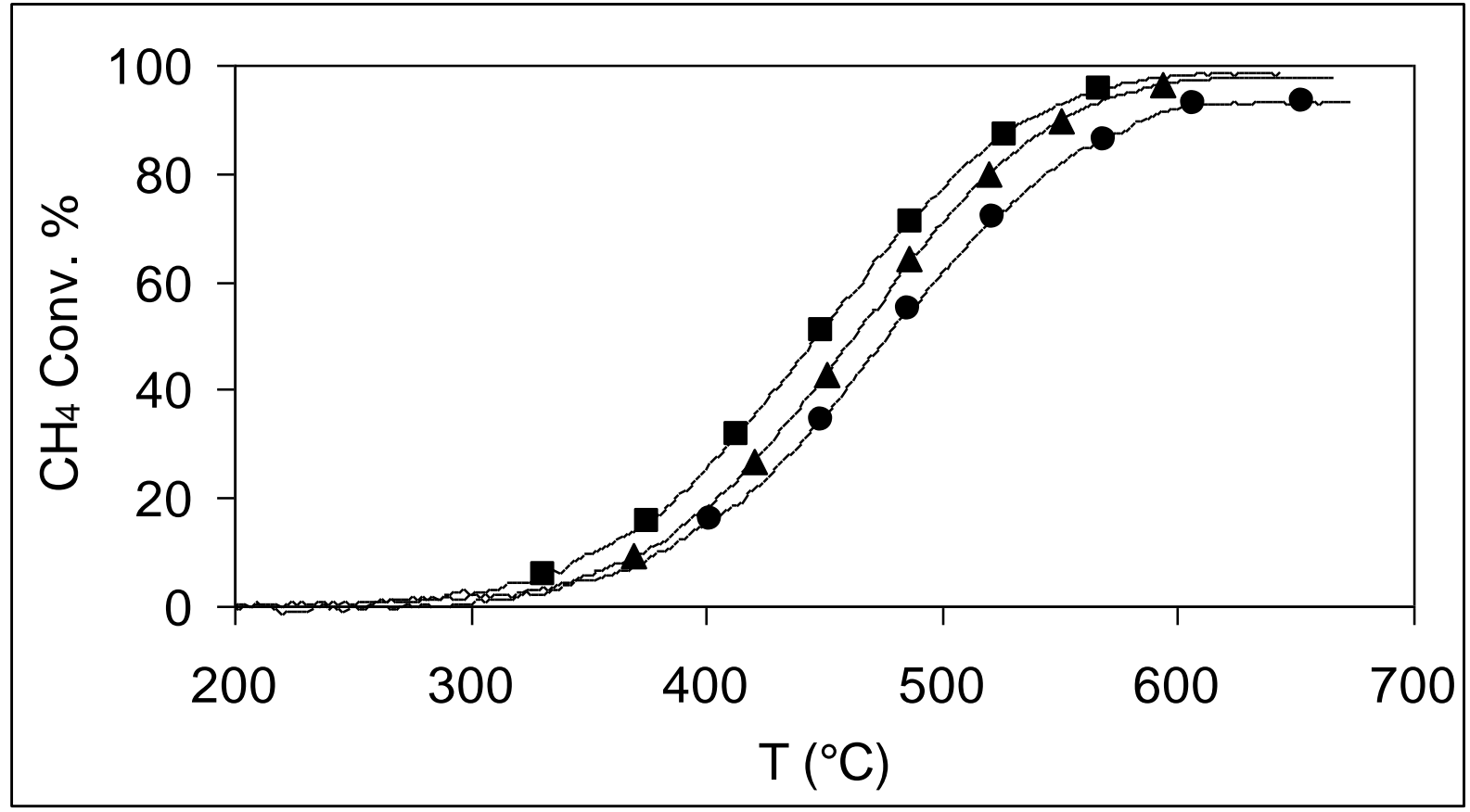

(c)

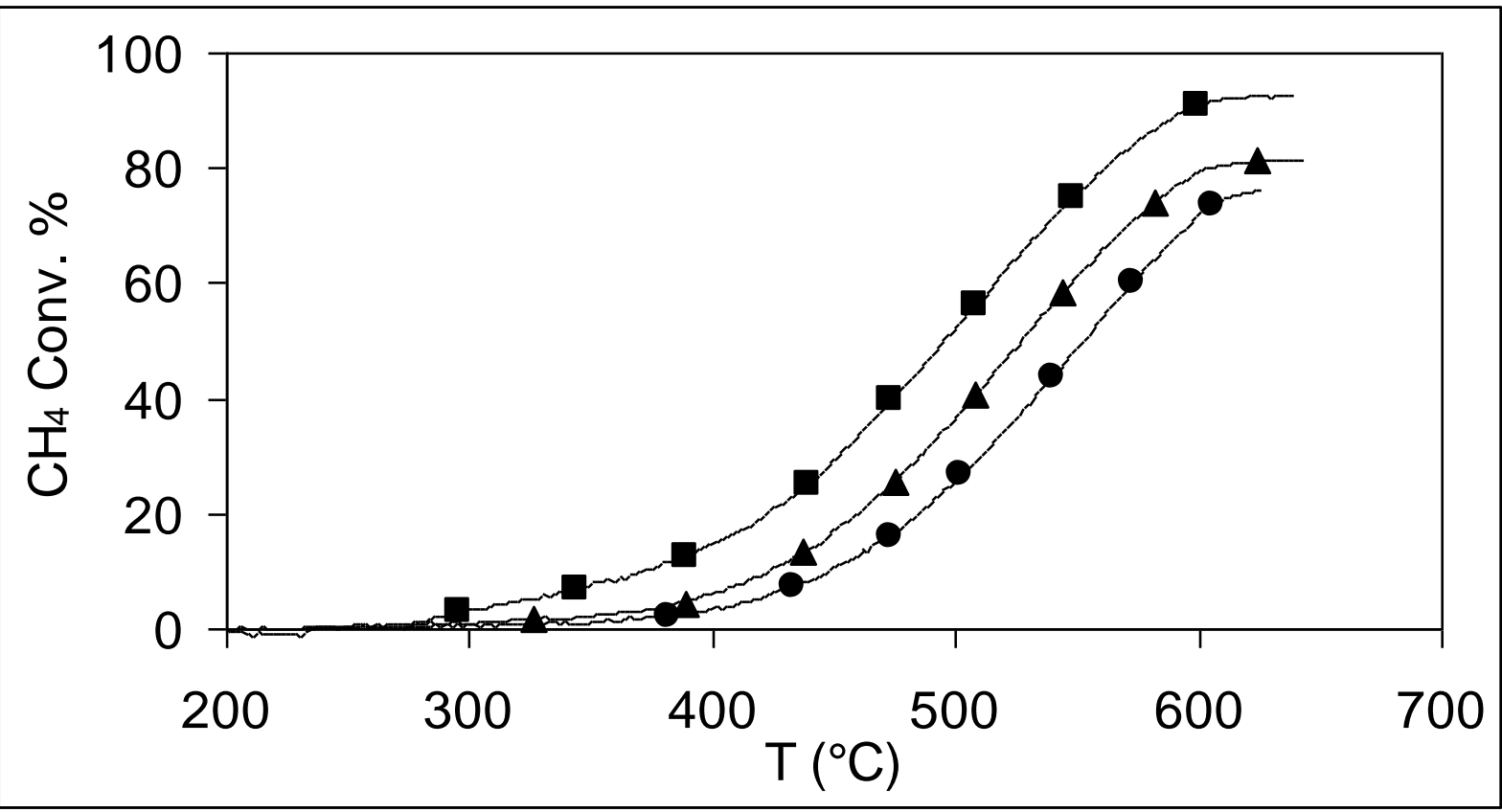


Fig. 3

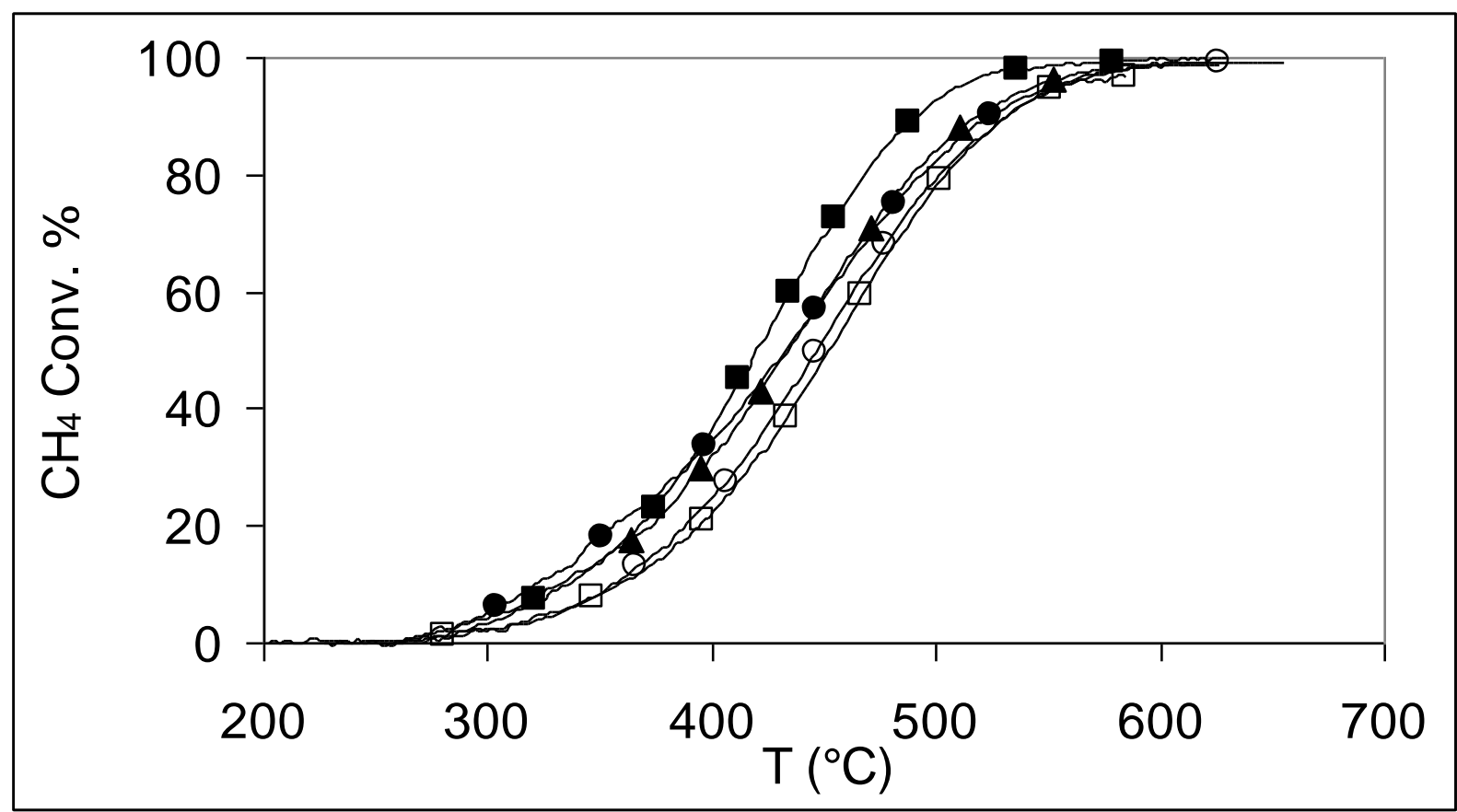

Fig 4.

(a)

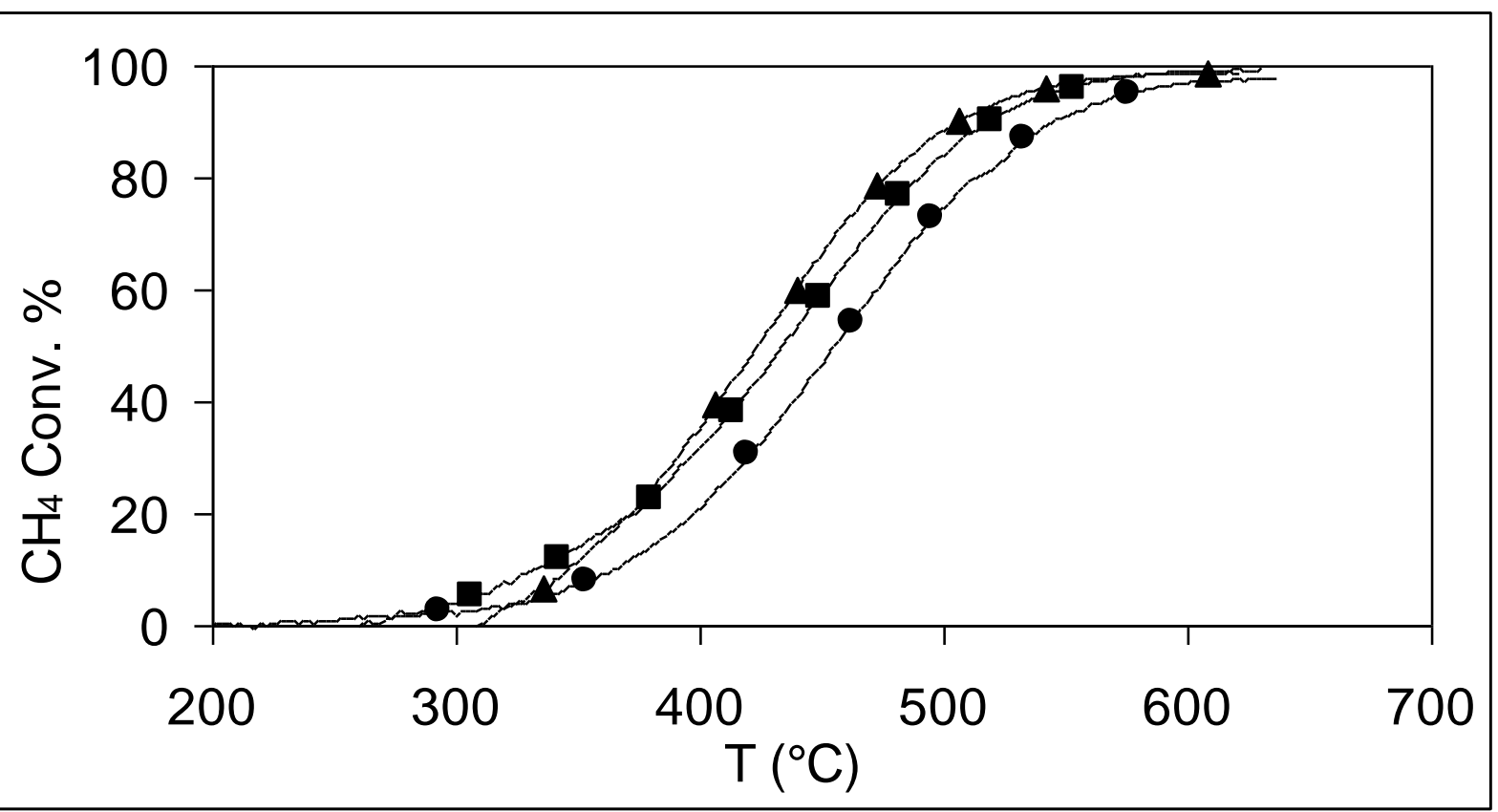


(b)

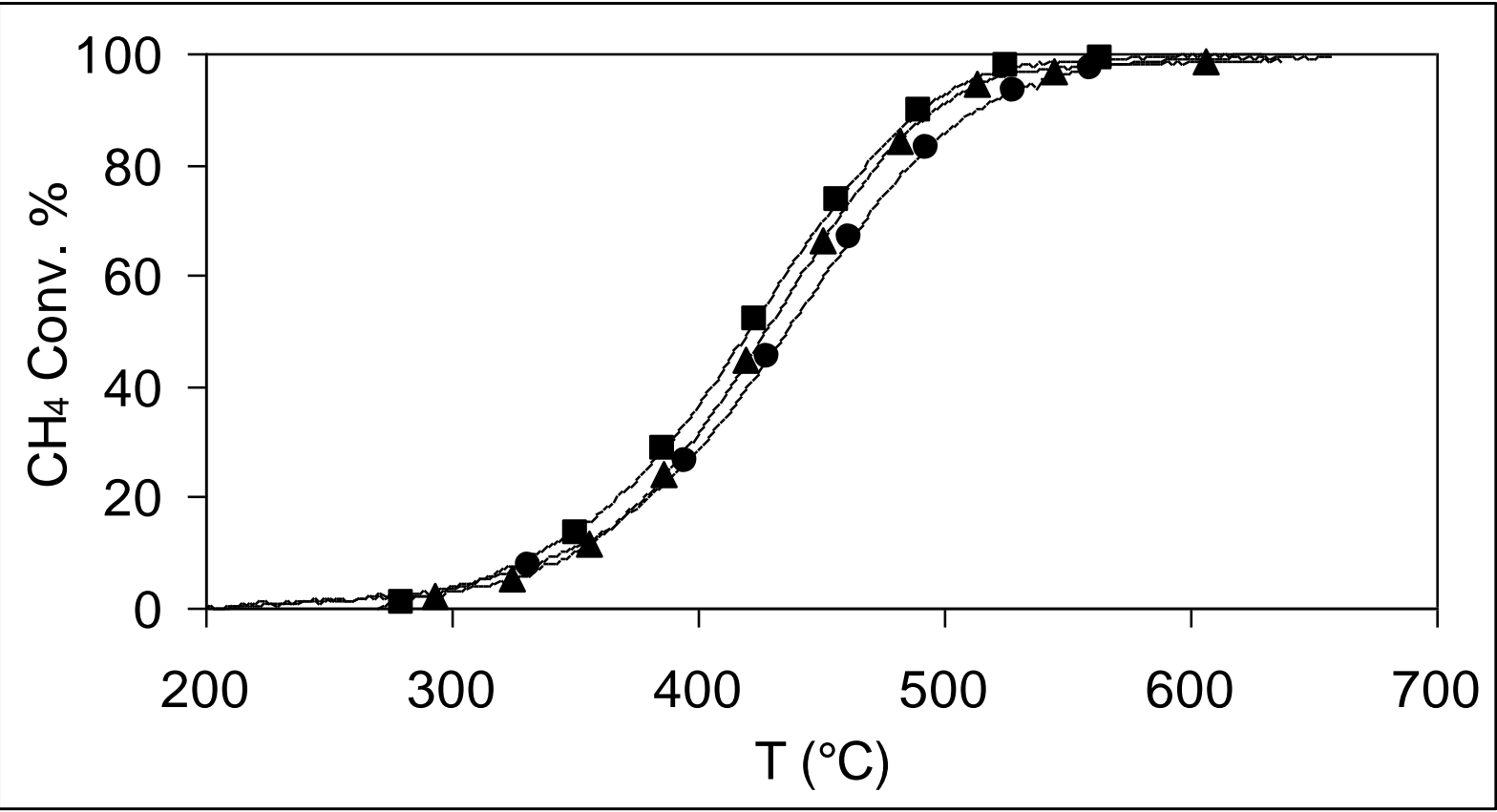

(c)

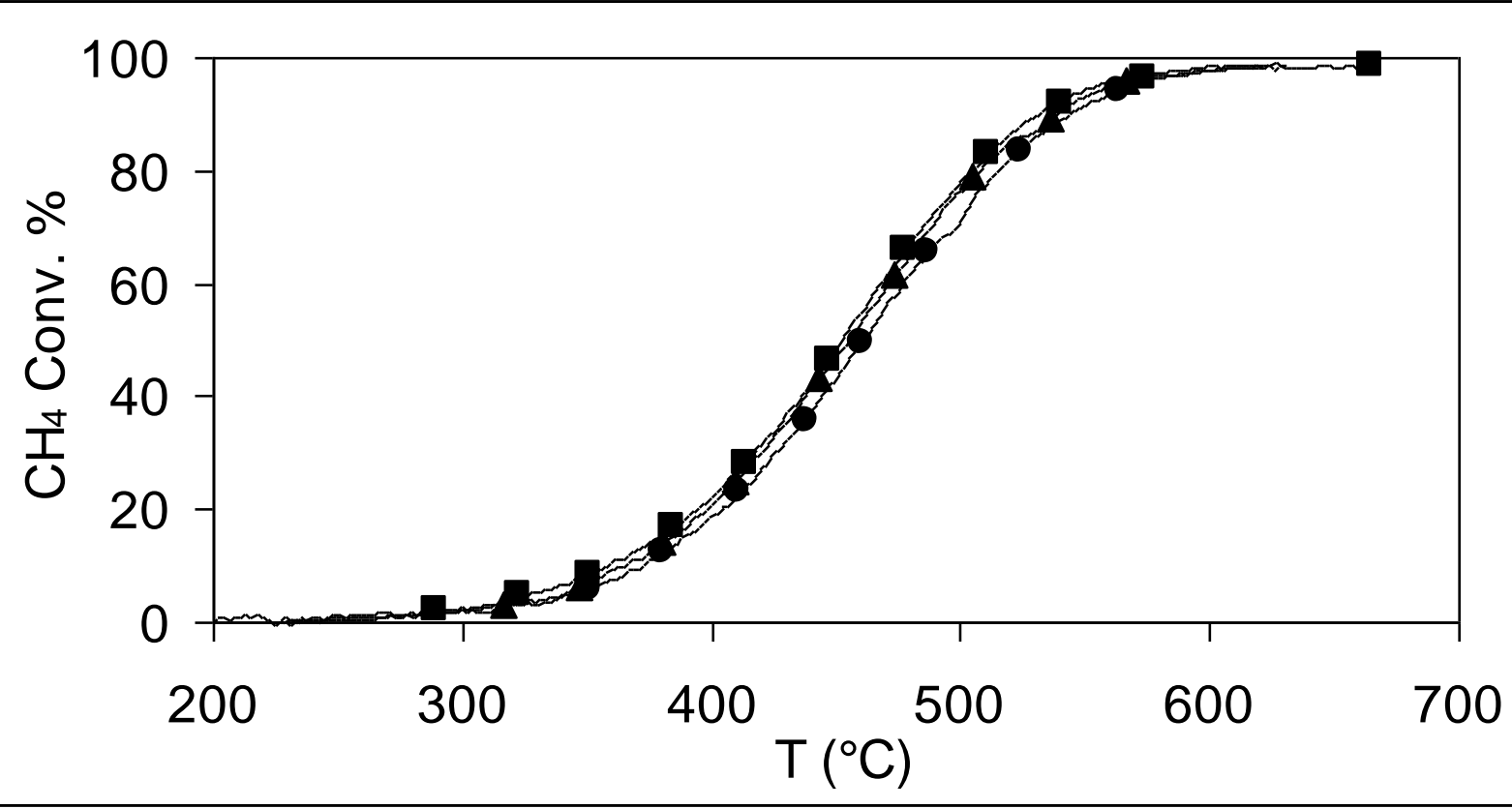


(d)

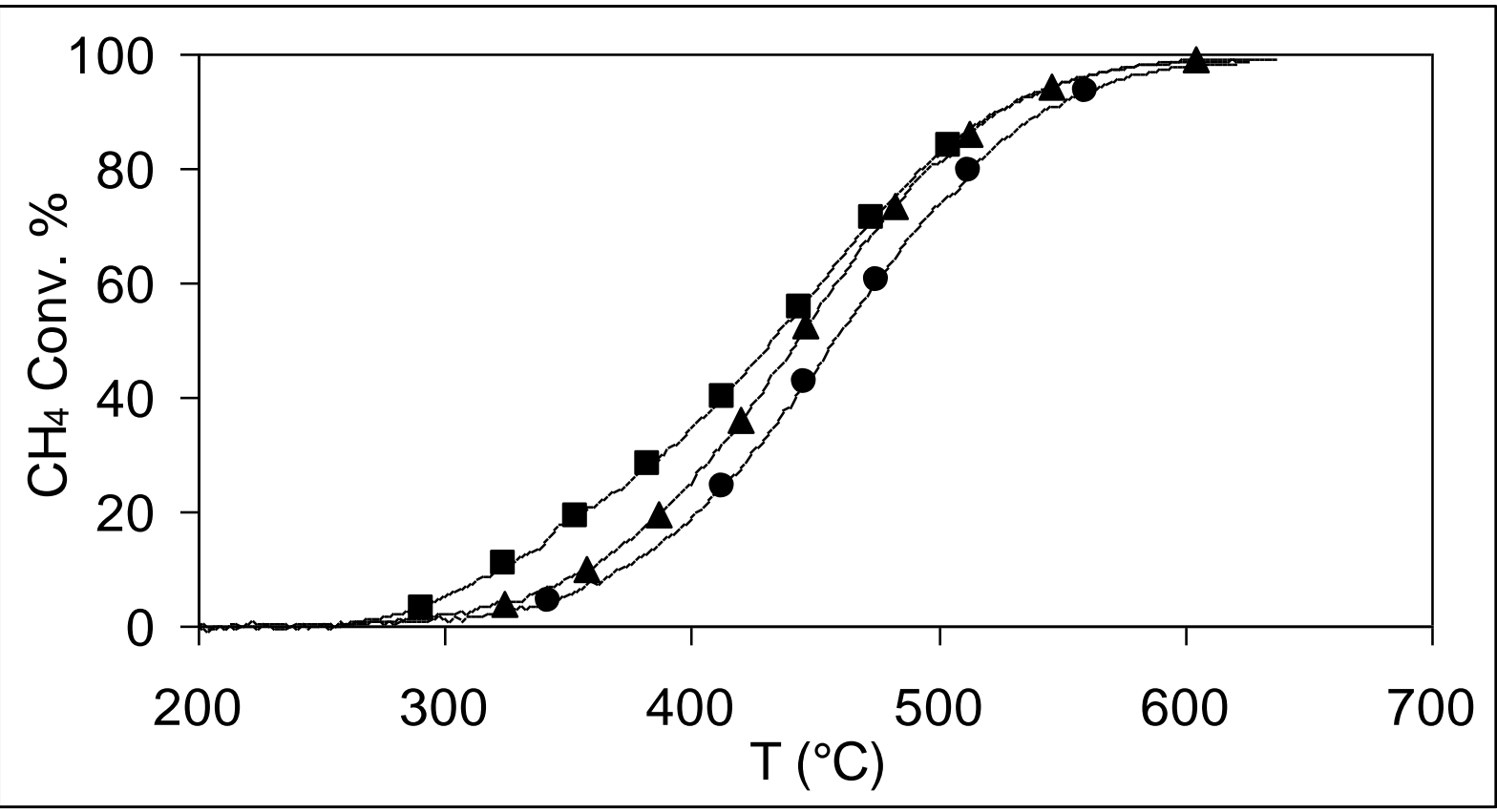

(e)

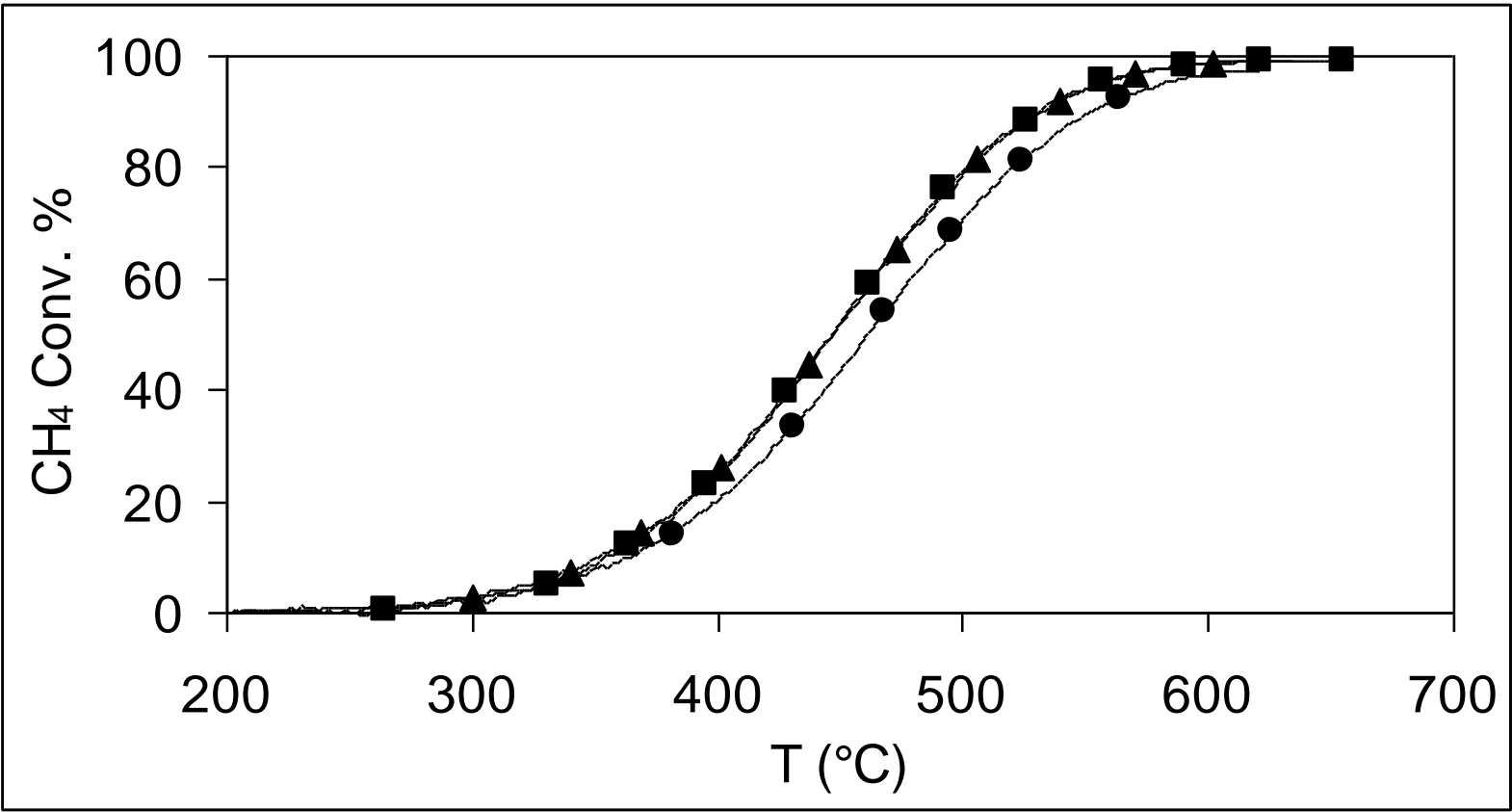


Fig. 5

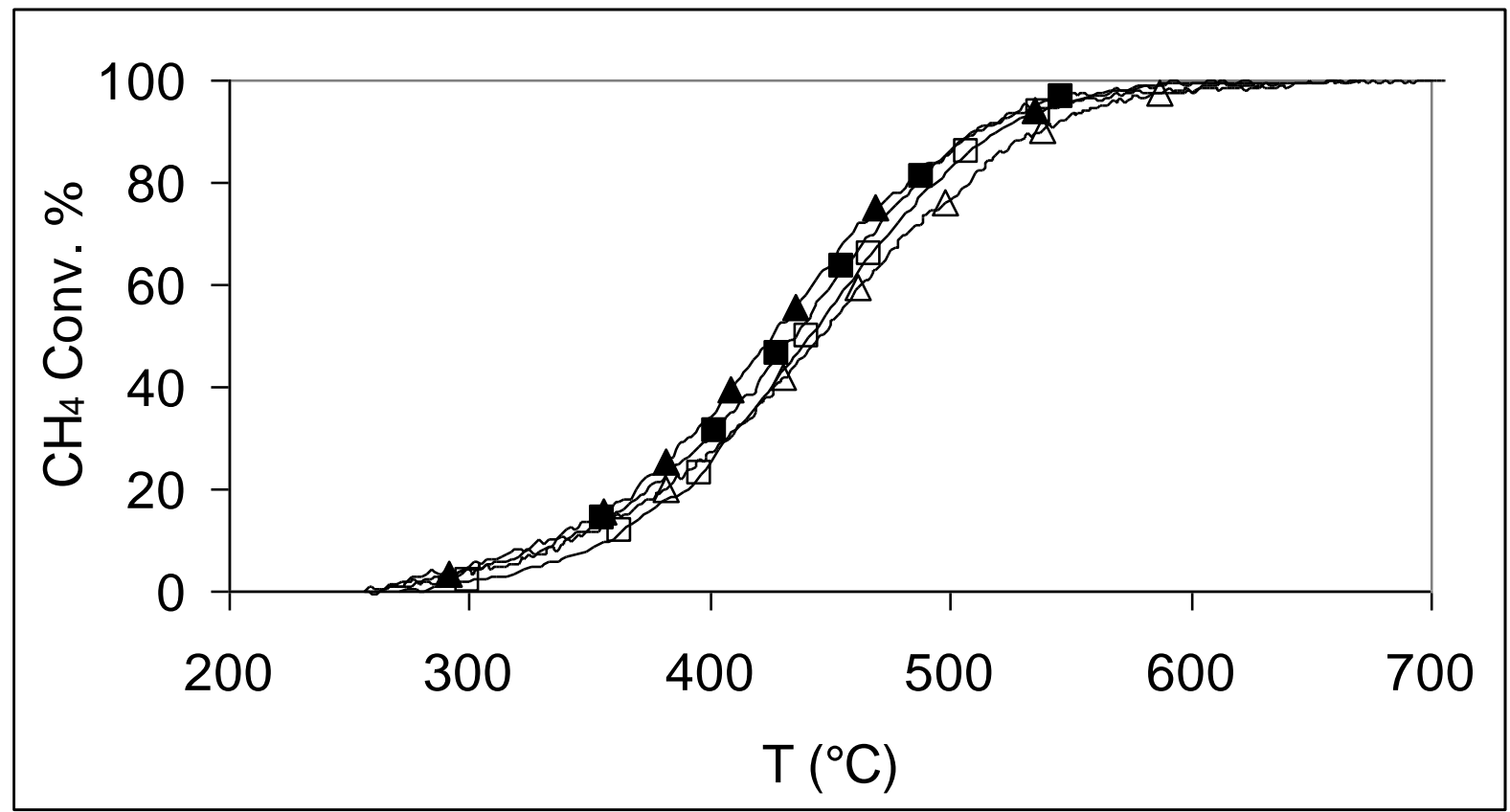

Fig. 6

(a)

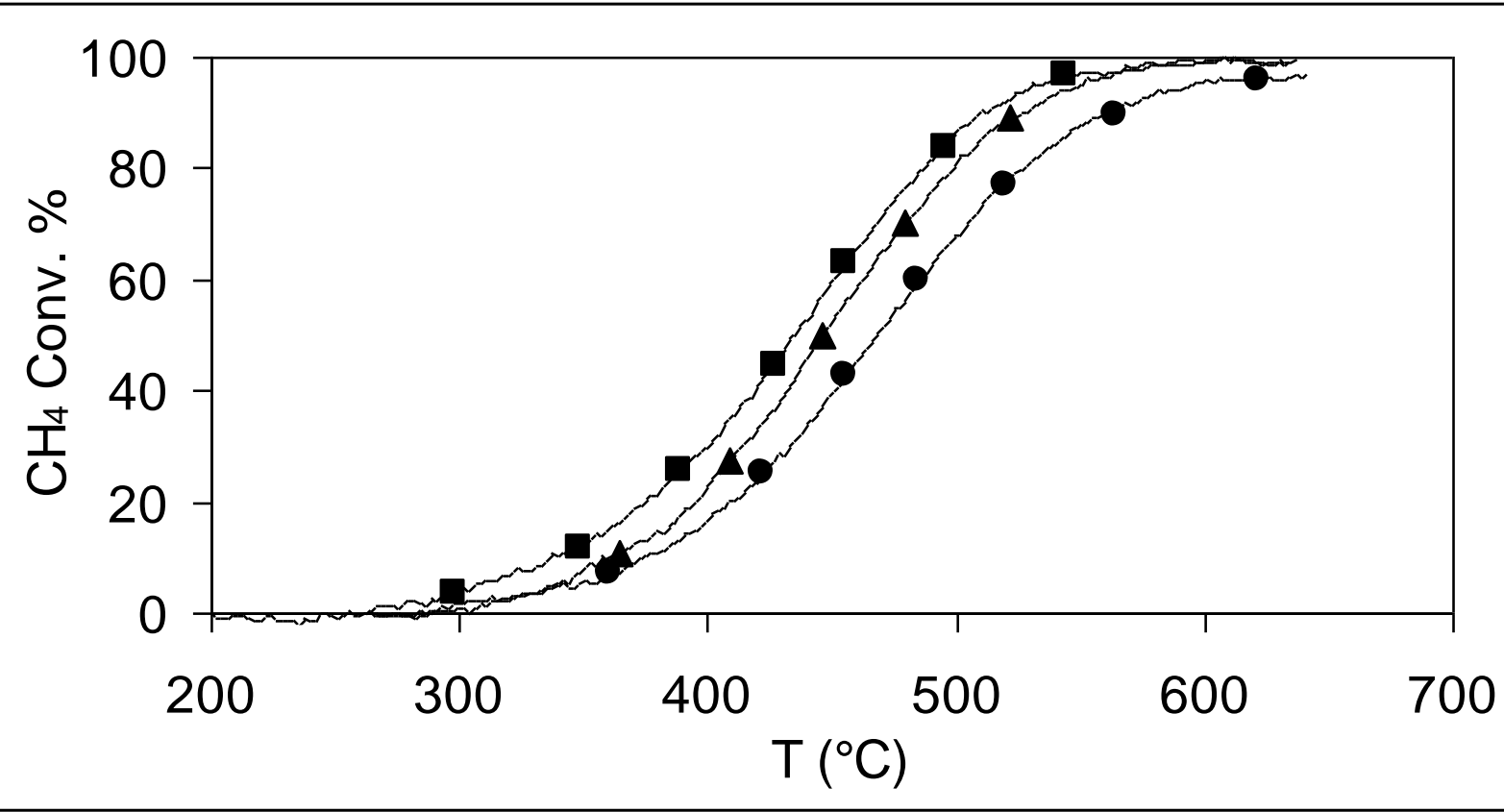


(b)

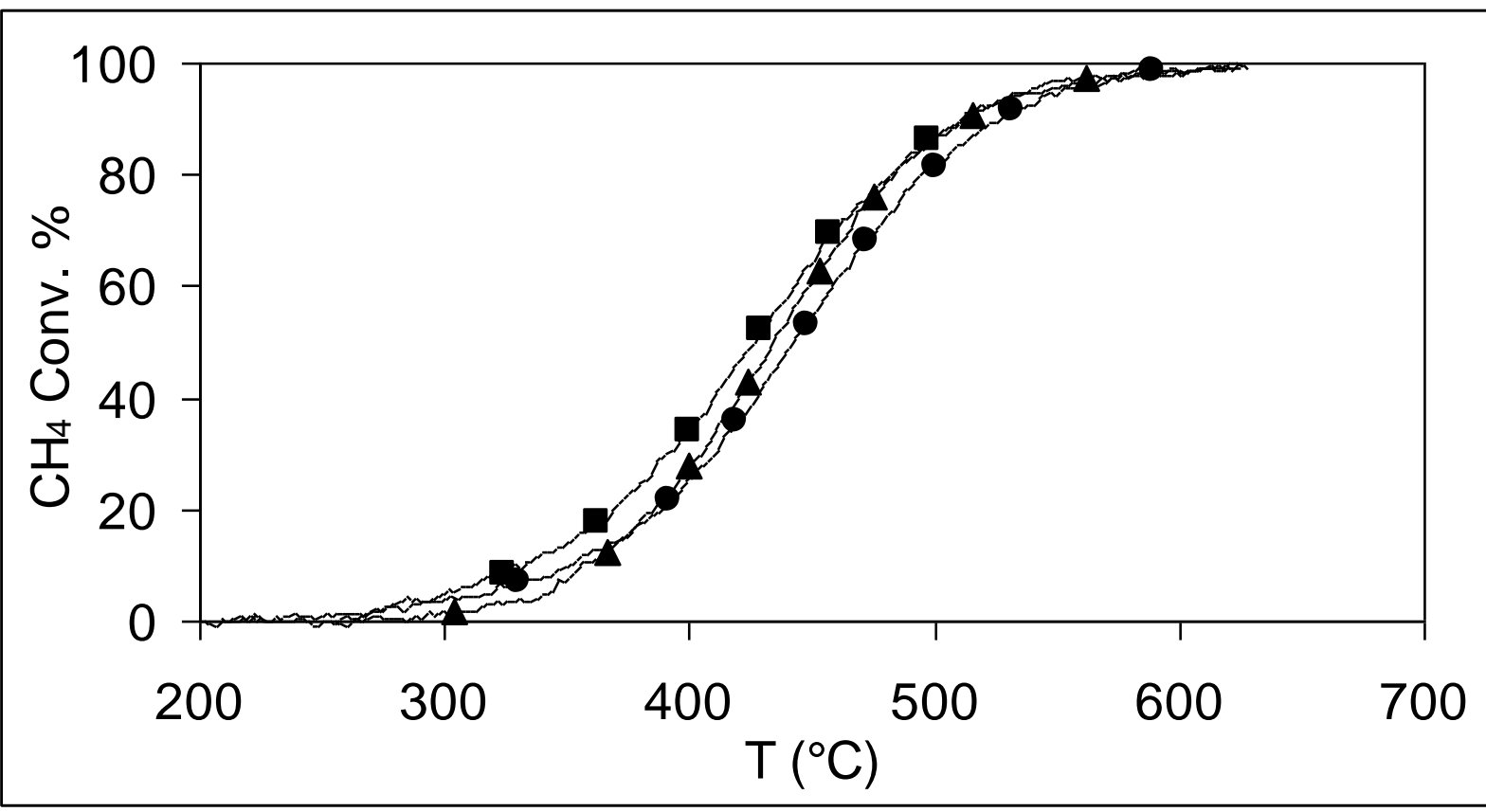

(c)

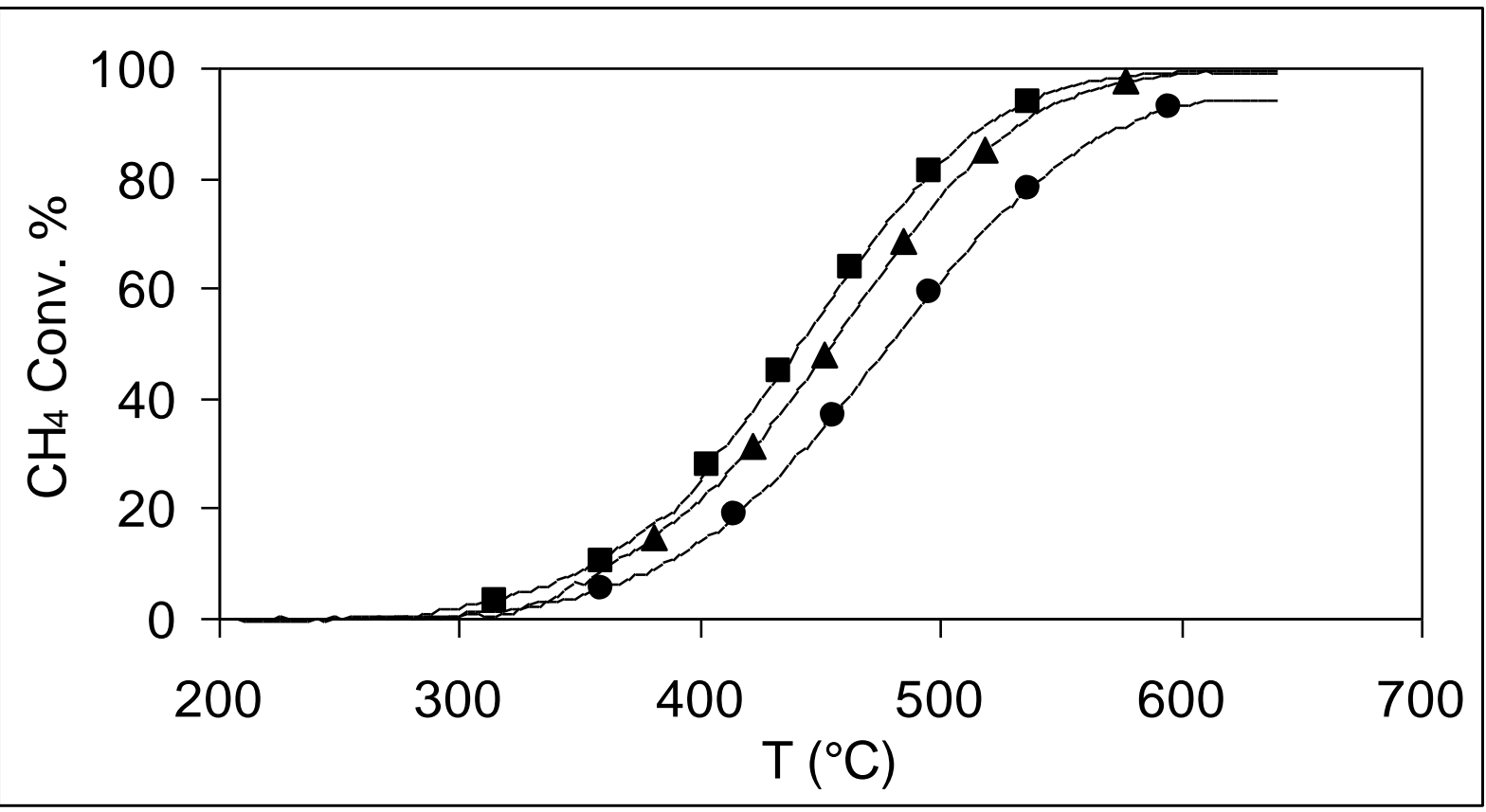


(d)

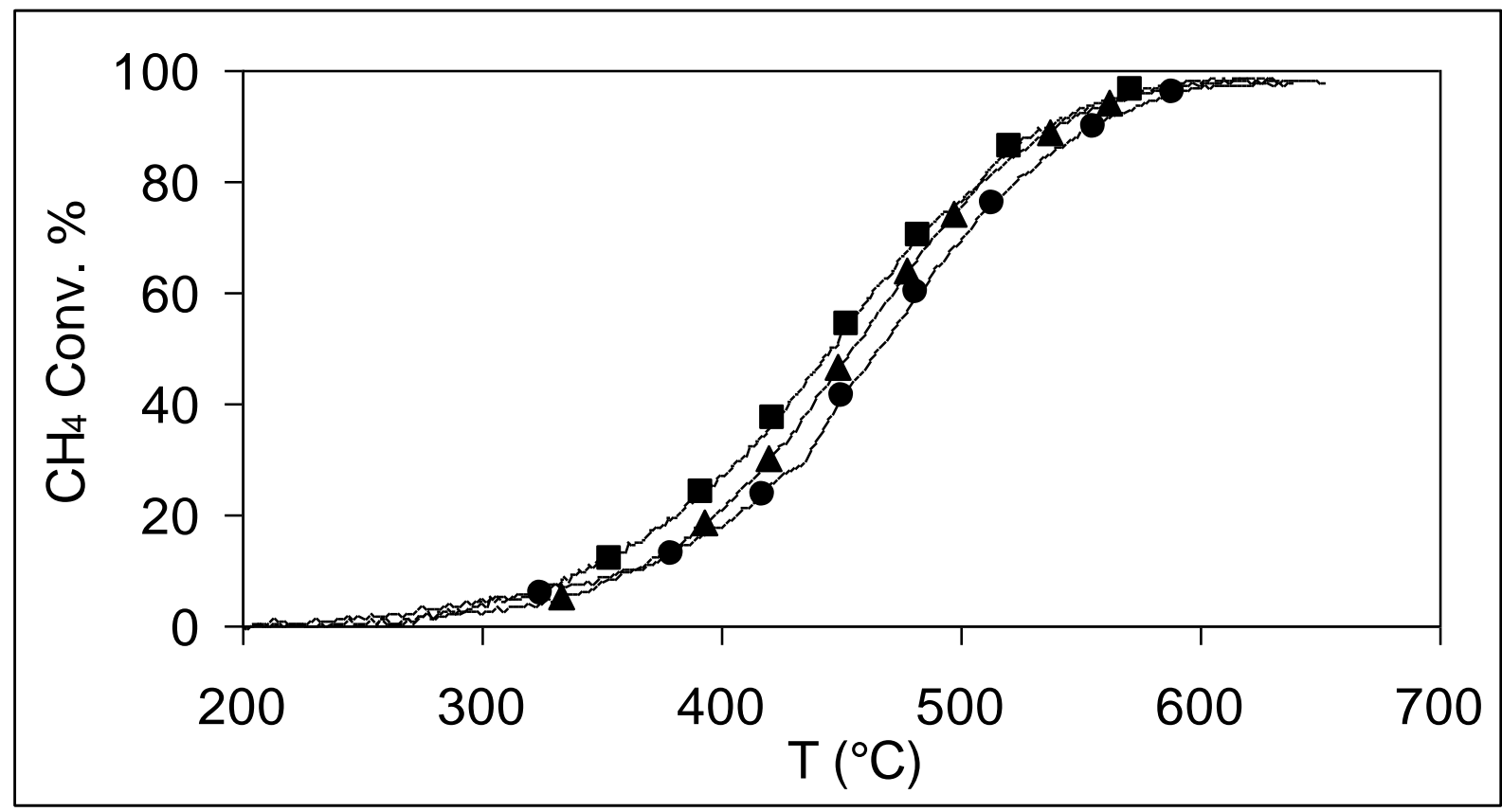

Fig. 7:

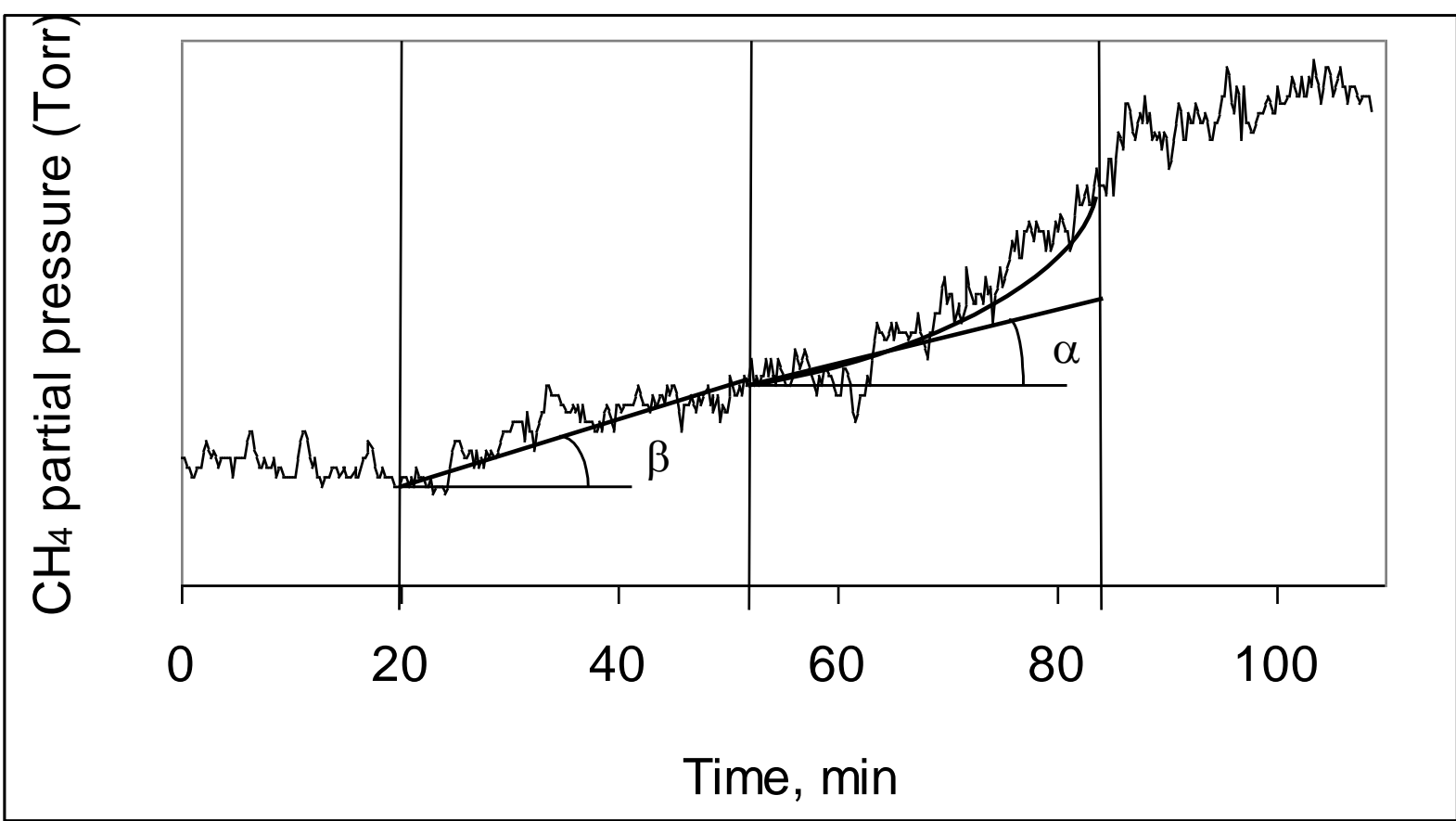

